\title{
Do Livelihood Typologies Influence Local Perceptions of Forest Cover Change? Evidence from a Tropical Forested and Non-Forested Rural Landscape in Western Uganda
}

\author{
Ronald Twongyirwe a, b, Mike Bithell a, Keith S. Richards a, W. G. Rees a, c \\ a Department of Geography, University of Cambridge, Downing Place, Cambridge CB2 3EN, England \\ ${ }^{b}$ Department of Environment and Livelihoods Support Systems, Institute of Interdisciplinary Training and Research, Mbarara University \\ of Science and Technology, P. O. Box 1410, Mbarara, Uganda. \\ 'Scott Polar Research Institute, University of Cambridge, Lensfield Road, Cambridge, CB2 1ER, England
}

\begin{abstract}
Validation of scientific findings from satellite remote sensing against local ecological knowledge could make the interpretation of forest cover patterns more robust. In this paper, we examine local perceptions of forest cover change in parishes around Budongo and Bugoma for a 30-year period (1985-2014), compare the results with those obtained from remote sensing (Twongyirwe et al., 2015), and interrogate whether the perceptions could be related to livelihood typologies.. First, we characterise household strategies for the entire landscape to place livelihood strategies of communities in deforestated areas in a broader local context. An in-depth questionnaire was administered to 706 households in 13 parishes situated in 4 Agro-Ecological Zones (AEZs). The data included household demographic characteristics, energy use, cropping and livestock husbandry, and seasonal time- and labour- budgets. Principal Components Analysis (PCA) and Cluster Analysis (CA) were employed to help identify dominant structures in the data. Secondly, the 375 households in 7 parishes around Budongo and Bugoma forests (part of the 706) responded to additional questions that sought their perceptions on the forest cover trend. The PCA results for the entire landscape show that significant variation amongst households is mainly related to the cultivation time input, on-farm income particularly from cropping activities, livestock husbandry, demographic characteristics, agricultural extension activities, and cultivation labour input. Hierarchical CA shows that households at the landscape level fall into about nine different types, with variation in spatial distribution. The analysis suggests that poor households do live near forested regions, and that the rural poor are more reliant on forest products than peri-urban populations. Regarding perceptions of forest cover change, the majority $(70.1 \%$ : $n=375)$ of the respondents in the parishes think that there has been a decline in forest cover, and this percentage is larger than the percentage of non-respondents (18.9\%), those that thought it had increased $(5.6 \%)$, not changed $(3.7 \%)$, and those that did not know (1.6\%). In addition, perceptions on forest change were significantly related to the household livelihood typologies $\left(\mathrm{X}^{2}=623.4, \mathrm{df}=4, \mathrm{p}=0.000\right)$ : respondents who perceived forest cover as having declined and those that provided no response belonged to cluster 2 ("low income mixed farming households"), which is also the dominant livelihood typology around these forests. While the data largely suggest that there is a remarkable agreement between remote sensing results and local knowledge on forest change, and that local people may play a big role in filling data gaps where a dearth of information is prevalent (or where remote sensing evidence is fuzzy), there is a clear signal that people in different social classes and age groups can have very different views on what the change in forest might be despite what Landsat data show. This might have policy implications if decision makers tend to come from the groups that are not likely to have perceived forest cover change, or base their judgement on views from certain social classes. This implies that it is important to have the remote sensing data available as a counter balance to local perception (and vice versa) and therefore these data should be considered concurrently.
\end{abstract}

Key words: Household Demographics, Time- and Labour-Budgets, Energy use, Cropping and Livestock Husbandry, Agro-Ecological Zones, Perceptions, Albertine Rift Landscape 


\section{Do Livelihood Typologies Influence Local Perceptions of Forest Cover Change? Evidence from a Tropical Forested and Non-Forested Rural Landscape in Western Uganda}

\section{Introduction}

Local perceptions of the historical and current status of forest cover can shed light on deforestation, forest gain and forest stability (Sheil and Wunder, 2002; Sunderlin et al., 2005; Agrawal, 2007). Local perceptions are often context-specific in nature, enhanced by individual and group interaction with their socio-ecological settings, and are often based on a need for rural survival (Dei 1993). Local perceptions of forest dynamics form a critical knowledge base that is especially beneficial in under-researched areas (Chalmers \& Fabricius 2007),for instance in the region around Bugoma Agro-ecological Zone (AEZ), and where evidence from scientific techniques such as remote sensing produces imprecise results (Hansen et al. 2013; Tropek et al. 2014). A combination of remote sensing data, GIS and local knowledge is ubiquitous in the literature (Lykke 2000; Southworth \& Tucker 2001; Yiran et al. 2012; Shackleton et al. 2013; Sulieman \& Ahmed 2013). Whilst remote sensing can provide quantities of forest cover change (useful in informing management strategies) (Lambin 2002; Twongyirwe et al. 2011; Hansen et al. 2013; Twongyirwe et al. 2015), we cannot obtain causal information and processes from these data (Chalmers \& Fabricius 2007). Such information can be revealed through interviews with local people (e.g. in Dalle et al. 2006; Chalmers \& Fabricius 2007; Shackleton et al. 2013). However, local people's perceptions of forest cover change could be influenced by livelihood conditions particularly if forests contribute to their survival (Dei 1993). For instance, while on- and off-farm incomes and related on- and off-farm activities may be indicators of rural people's dependence on forests to meet their day-to-day needs, the age of a respondent will affect trends that have been witnessed/recollected/perceived over the last 30 years (revealed by this study). Perceptions of forest cover change are therefore examined below in the light of rural livelihood characterisation.

Agriculture is the backbone of Uganda's economy (Fan and Zhang 2008), and the agricultural sector continues to be viewed as a vehicle through which economic growth and development can be achieved, as stipulated in the National Development Plan in the Uganda Vision 2040 (G.o.U 2012). Most agricultural production is associated with poor rural farmers who account for over $85 \%$ of the total population (UBOS 2007). Rural livelihoods are embedded in complex agroecological systems, and are dependent on natural resources (e.g. forests, savanna grasslands). Farmers seek to maximise agricultural production, maintain a healthy household, cope with seasonal fluctuations, exploit market opportunities, manage risk through diversification to other economic activities, and accumulate wealth for their welfare (Bogdanov et al. 2008; Tesfaye et al. 2011; Chilongo 2014). The majority must exploit the natural resource base to practice their livelihoods, resulting in land cover changes (de Sherbinin et al. 2008). These changes may include deforestation in some parts of the country. In order to illuminate the key drivers of deforestation it will be important to understand the livelihood characteristics of households where dramatic deforestation has occurred (e.g. Budongo and Bugoma Agro-Ecological Zones [AEZs]; Twongyirwe et al. 2015), and contrast them with regions without forest (e.g. the semi-arid and the peri-urban AEZs in this study).

There is a general lack of empirical understanding about how households in the Northern Albertine Rift Landscape use their resources in the face of changing economic and social conditions, yet this is critical for policy development, especially for designing sound agricultural and forestry policies (Pacini et al. 2014). Uganda's national censuses are conducted every decade, but they do not ask relevant questions for this purpose, and the raw data are unavailable for ethical reasons. This study therefore provides data for characterising rural livelihoods drawn from a new survey of households, including wide-ranging questions about household demographic characteristics, cropping and livestock husbandry, energy use, seasonal time and labour budgets. 
The focus of the research is at the parish scale (each of which includes two to four villages, see Table 2) for two main reasons. 1) Local people's day-to-day activities are often place-specific (Ostrom and Nagendra, 2006); they may therefore be knowledgeable of events that occurred within their parish, but not at a larger 'regional scale' (which is $>5$ times the size of their parishes). 2) Parish-scale analysis is considered as the finest resolution to represent local heterogeneity and has been used as a unit of sampling by similar forest cover change studies in Uganda (e.g. Sassen at al., 2013). Villages tend to have few clustered households, and may therefore not provide representative data to understand the heterogeneity of local-scale processes. Details of sampling are provided in the methods section.

The overarching objective is to construct settlement and activity patterns (livelihood typologies) across the landscape with a view to understand potential factors contributing to forest loss outside the protected forest estate, on privately-owned landscapes, and to shed light on people's perceptions of forest cover change with a view to establishing whether these are related to their livelihood typologies. Specific research questions addressed include:

1. What are the key discriminators of livelihood characteristics in the landscape?

2. Are there distinctive household types, based on socio-economic characteristics in the region?

3. Are there identifiable spatial relationships of the household types to the AEZs?

4. What are local people's perceptions on forest cover patterns in their parishes?

5. Are local people's perceptions on forest change influenced by their age and livelihood typology?

6. How do local people's perceptions on forest change compare with changes reconstructed using satellite remote sensing for the 30 -year period?

For the purpose of this paper, a household is defined as a primary unit of domestic production, reproduction and decision-making (de Sherbinin et al. 2008). Typically, it consists of a group of people of various ages living together in the same housing unit, and eating from the same 'pot', and usually belonging to the same family. The surveys were conducted at household level, and only members living in the household at the time of the study were included in the household demographic analyses. Those that had migrated to work or study or because they are married were not included. A household livelihood type then refers to a number of households that have a similar multi-dimensional set of socio-economic characteristics, but that distinguish them from other households with different characteristics.

To some degree, household types differ between AEZs. The latter are defined using remote sensing analysis and a supervised classification procedure that is able to indicate wide-spread forest loss outside the large protected forests (Twongyirwe et al. 2015). Climatic conditions around Budongo and Bugoma forests are dissimilar, and these are distinctive AEZs (Table 1); they also have different types of cash crop, and different local population compositions. In order to understand how livelihoods vary between forested and non-forested areas in the study region, semi-arid (parishes in Buliisa) and peri-urban AEZs (parishes in Hoima and Masindi towns) were included in the study.

In line with the Oxford English Dictionary, we define perception as "the way in which something is regarded, understood, or interpreted; intuitive understanding and insight". In this context, knowledge of forest cover change may be built on individual 'perceptions' of the environment, and perceptions underpinned by actions, attitudes, livelihood and beliefs could shape their understanding of existing information.

\section{Data, Materials and Methods}

\subsection{Description of study area}

Research was conducted in the Northern Albertine Rift region in western Uganda, approximately between $1^{\circ} 18^{\prime}-2^{\circ} 11^{\prime} \mathrm{N}$ and $30^{\circ} 40^{\prime}-31^{\circ} 52^{\prime} \mathrm{E}$, with an estimated area of $14,100 \mathrm{~km}^{2}$. The Albertine Rift is one of the most important conservation regions in Africa with extensive areas of both protected and unprotected forest (Owiunji and Plumptre 1998; McLennan and Hill 2012), 
abundant bird species, high plant and tree species diversity (Eilu et al. 2004), and an unmatched animal species diversity, most of which are endemic to this ecosystem (Plumptre et al. 2007).

The landscape has a gently sloping terrain, and a tropical climate with two rainfall peaks, in March to May and September to November (Eilu et al. 2004; Seimon 2013). The region's ecosystem is threatened by widespread deforestation especially on privately owned landscapes that lie outside protected forest estate: the protected forests have remained intact (Twongyirwe et al. 2015). Small-scale agriculture is the main way of life, with some limited commercial farming to provide raw materials for sugar, tea and tobacco industries in the region (Nangendo et al., 2010). In contrast, people living in the urban centres are more involved in trading-based activities than agriculture. Oil was discovered in the Albertine Rift in the mid 2000s, and construction of an oil industry is under way in the region. The landscape has attracted many government and nongovernmental conservation and development organisations (authors' observation during fieldwork). It is not clear how development goals and conservation will work together in this landscape, or how this will influence livelihoods.

\subsection{Selection of Study Parishes at the "Landscape scale"}

Fieldwork was conducted from $1^{\text {st }}$ October, 2013-31 ${ }^{\text {st }}$ March, 2014 in 13 parishes in 4 AEZs (Figure 1 , Table 2). Parishes were selected initially by analysing remote sensing imagery to identify regions where significant forest loss has occurred (Twongyirwe et al. 2015). The regions immediately adjacent to the protected forest blocks presented an interesting case as they had experienced dramatic deforestation. We also selected parishes from the semi-arid and peri-urban AEZs as part of the design to compare livelihood characteristics in the forested and non-forested regions. Approximately 20 parishes were initially selected using Google Earth and existing maps of the region.

\section{Table 1 Description and characteristics of the Agro-Ecological Zones}

\section{Figure 1 Map of study area showing the Agro-Ecological Zones (AEZs) where fieldwork was undertaken: A) Semi-arid zone, B) Budongo, C) Peri-urban zone, D) Bugoma}

These were then assessed for accessibility, particularly the state of roads in rainy conditions, taking advice from experts in Kampala who have worked extensively in the region (e.g. from the Wildlife Conservation Society and the Albertine Rift Conservation Society), and from the district headquarters once in the field. Parishes where this was likely to be a problem were excluded, as were those where it was considered likely to be difficult to obtain essentials such as fuel, foodstuffs and first aid items (medicine) when these could not all be transported from Kampala. Finally, it was necessary to consider the safety of the research team, given that fieldwork was conducted in a period of political instability in the eastern part of Democratic Republic of Congo, and an influx of refugees was occurring into the region via Lake Albert. Given these additional criteria, the 13 parishes presented in Table 2 presented cases that it was practical to survey.

\section{Table 2 Sampled parishes in the four Agro-Ecological Zones}

\subsection{Sampling Design: Transects and Randomisation}

Within the selected parishes, the aim was to obtain a robust and unbiased sample of households to participate in the survey. This could not be achieved by locating households on high resolution remote sensing imagery and sampling at random, because of the prohibitive cost of the imagery; nor by using national census data because the household-level census data are not available for public use, and in any event, the last census was more than a decade out of date. However, a truly random sample would have resulted in very high transport costs. Instead, therefore, a transectbased randomisation technique was employed during fieldwork to select participating households.

Four graduate Research Assistants (RAs) were recruited from Makerere University and the Institute of Tropical Forest Conservation (ITFC) and were thoroughly trained in advance on administering the questionnaire including the ethical considerations and risk assessments. Once in the field, four field guides were recruited in each parish. The RAs and guides set off (walking) in four canonical compass directions from the approximate centre of the parish. The household inclusion technique was different for each assistant. The first took odd numbered households along 
a transect, the second included even numbered households, the third took prime numbered households (e.g. every $1^{\text {st }}, 3^{\text {rd }}, 5^{\text {th }}, 7^{\text {th }}, 11^{\text {th }}$ etc), while the fourth took every third in a line. These guidelines were intended to avoid consciously selecting certain households, mainly in crowded settlements - but the rules were relaxed if the households were located more than $1 \mathrm{~km}$ apart. Distances between sampled households varied widely (between $50 \mathrm{~m}$ to $1 \mathrm{~km}$ ), but it was possible to sample across different villages on the transects with this technique. Availability of a household leader (or adult respondent) willing to participate freely in the survey was also required, but the refusal rate was extremely low with only a handful in each area, usually because a person did not have the time to participate. GPS coordinates of the surveyed households were obtained (using Garmin GPS62), accurate to at least 2m.

\subsection{Household Questionnaire Survey}

Based on the above sampling design, questionnaires were administered to a total of 706 households (Table 2). RT (lead author) oversaw the process and gathered specialist information from key informants. Within each parish, the Local Council 1 chairman ("LC1": lowest administrative unit, at village level) of one of the villages assigned a field guide to each of the RAs, partly to introduce the RAs to the respondents and to assure them of the local council leader's approval, but also to build rapport between the RA and respondents. The field guides also interpreted some questions where a language barrier was problematic.

Surveys were conducted at the respondents' homes, usually with the household heads, but in a few cases with the most senior and knowledgeable of the adults available. The questions covered household demographic characteristics (e.g. age, gender, off-farm income), energy use, cropping and livestock husbandry (e.g. farm size, crop histories, yields, number of and income from livestock, land tenure), and seasonal time- and labour- budgets. The purpose of the study was explained to the respondents, and anonymity of response, free, prior and informed consent (FPIC), confidentiality and data protection were all emphasised. Respondents were informed of a possibility to withdraw from participation at any stage they wished. Each household interview lasted, on average, between 45 minutes and 1 hour.

The languages used in the survey were English and Runyoro, with Kiswahili and some other dialects occasionally being required. The region has diverse tribes from within and outside the country. Where more specialised dialects were required, the field guides worked as interpreters. It was therefore essential that RT and the RAs spoke the major local dialects (Runyoro in Hoima and Masindi, and Rugungu in Buliisa), but even more important that the field guides were fluent in local dialects.

A wide range of variables were measured by the questionnaire survey, and these include variables that are both continuous (Supplementary Information 1) or categorical (SI 2) based on how the data were measured. The 83 variables in SI 1 are arranged in the order in which they were ranked according to the Principal Components Analysis (see sections 2.6.1 and SI 3).

Pilot study: The questionnaire was piloted with 24 households in Nyabyeya parish in Masindi district. This was to check for clarity of questions, duration of interview, and for the RAs to obtain hands-on-practice, especially in recording the information and keeping within the interview time limit. It was not necessary to adjust the questionnaire after the pilot, since all questions were found relevant, but slight changes were made to the ways in which some questions were asked. For instance, instead of asking if the respondent was a migrant/native, we asked for their tribe. (The native tribes in the region are Banyoro (in Hoima and Masindi) and Bagungu in Buliisa, so all other tribes were categorised as migrant irrespective of how long their members had lived in the region.

\subsection{Parish-level Forest Change Perceptions Survey}

We selected 7 parishes (no. of respondents $=375$ ) within a radius of 0 to $15 \mathrm{~km}$ from Budongo (Figure 2a) and Bugoma (Figure 2b) forests, a subset of the 706 households described in section 2.2. For these households additional questions pertaining to forest cover change were administered (e.g. we asked the respondents to tell us if they perceived forest to have increased/declined/not changed in the last 30 years within their parishes, without necessarily asking for their opinion on the magnitude of the change). Because of the ethical related 
implications of deforestation, it was further stressed that the respondents had an option not to provide a response about forest cover change if they did not wish to.

\subsection{Triangulation: Field Observations}

The questionnaire was designed in such a way that some questions would 'self-check' previous responses; or that there should be a logical correlation as a form of "triangulation" (Erzberger and Prein, 1997). An example of a direct check is that we enquired about incomes spent on-farm from off-farm sources, and then tracked this when we asked for a breakdown of expenses on cropping and livestock activities. An example of a logical check is that the household should not use labour greater than the number of members that could reasonably provide it (e.g. when the elderly and infants are excluded), otherwise, extra labour would have to be out-sourced. Furthermore, the field team camped within the study parishes, and observed first-hand how people went about their dayto-day activities, including collecting firewood for cooking, fetching water, and working in the gardens, etc. This was useful to build rapport, but also enabled us to judge if responses were reasonable. In any case, all data were recorded as received, with the hope that "inaccurate data" might emerge as outliers. The results show rather consistent livelihood indicators, suggesting a successful data gathering campaign. The study was also supported by an extensive literature review of documents in government libraries (e.g. previous census records), key informant interviews, and published academic literature.

\subsection{Data Processing/Analysis and Statistical Modelling}

Descriptive statistics were computed for all continuous variables assessed in the questionnaire, which are mostly non-normally distributed (Kolmogorov-Smirnov test, $\mathrm{p}<0.05$ ). This exploration of the data was useful for understanding which statistical tests might be appropriate. Because the data-set consists of many variables (as shown in Supplements 1 and 2), it is useful to continue by screening the data for redundant variables. The questionnaire data provided a total of 83 continuous variables, with 706 observations of each. In comparison to much published literature (e.g. Bidogeza et al. 2009; Costard et al. 2009; Diwani et al. 2013; Chilongo 2014), this constitutes a large amount of data, for which variable dimensional reduction is desirable prior to further analysis, but for which the total size of the data matrix provides confidence in the analytical outcomes. Dimension reduction was achieved using Principal Components Analysis (PCA) (using SPSS version 22) (see details in Supplment3). The reduced dimensional data-set from the PCA was then divided into clusters using a hierarchical agglomerative method.

Because the many variables subjected to PCA are measured in different units, and have very different absolute values, they were re-scaled using z-scores, so that they all had zero mean and unit variance. Each variable then contributes on average $(100 / n) \%$ to the total (where $n$ is the number of variables). The 'significant' PCs should contribute more to the total variance than this, and one method of determining how many components to retain from the analysis is to select only those for which the variance contribution is $>100 / \mathrm{n} \%$. Using the scree diagram (Figure 3), Kaiser's rule (significant eigenvalues should be greater than 1) and the principle that the components selected should together explain at least $70-80 \%$ of the total variance (Jackson 1993; Bell et al. 2015), we estimate that the first 17 PCs should contain most of the meaningful information describing household variation, leading to a total variance retained of $75.4 \%$. These (17) were the components that were used in the cluster analysis, although a total of 22 "new variables" (Principal Component: PCs) fulfilled the $1.2 \%$ variance cut-off based on the rules above. The scree diagram shows some slight breaks of slope (at PC 3, PC6, PC12, and PC22), after which there is a gentle decline, and remaining PCs account for less than $1.2 \%$ of the variance [(100/83)\%]. The results are shown in tabular form in SI 4.

Different variable groupings correlate strongly with each component and are interpreted (as variable category) and highlighted in the Table in SI 5. The components are then labelled according to the variables that load strongly onto them. Essentially, significant variation in the households is mainly related to the cultivation time input (PC 1), on-farm income particularly from cropping activities (PC 2), livestock husbandry (PC 3), demographic characteristics (PC 4), agricultural extension activities (PC 5), and cultivation labour input (PC 6), which account for $21.6 \%$, 8.6\%, $5.7 \%, 4.9 \%, 4.4 \%$ and $3.7 \%$ of the total variation respectively (Tables 3 and 4 ). By contrast, 
livestock income (PC 20), usage of forest products (timber and poles) (PC 21), and off-farm income (PC 22) were the least important variables contributing only $1.5 \%, 1.4 \%$ and $1.3 \%$ to the total variation in the data respectively (Tables SI 4 and SI 5). Table SI 5 includes definitions of the 22 Principal Components.

Selecting the number of clusters is a somewhat subjective, exploratory process; choosing different numbers of clusters can result in different conclusions about classification results. Boundaries between clusters can be drawn at similarity levels just before clusters are combined, and the outcome generally favours a balance between too few clusters (with high internal variance) and too many (which complicates interpretation) (Vickers et al. 2003; Holland 2013). Here Nine distinct clusters were identified, based on the occurrence of 'long stems' (shown by the point at which the blue lines intersect with the red line - Figure 5) at the rescaled cluster combined distance of approximately 11, allowing a clear separation of household types according to livelihood characteristics. The clusters have a variable number of sub-clusters. In particular, cluster 2 is the largest, accounting for $30.2 \%$ of the total number of households $(n=706)$ and having a sequence of four sub-groups that join together at increasing levels of dissimilarity. Cluster 7, which accounts for $8.8 \%$ of all sampled households, has two groups that join at a relatively low level of similarity. The remaining clusters $1,3,4,5,6,8$ and 9 account for $13.5 \%, 12.5 \%, 12.6 \%, 5.1 \%$, $5.2 \%, 3.5 \%, 6.1 \%$ of the total number of households $(\mathrm{n}=706)$. Only $2.5 \%$ of the households were unclassified due to missing data. The characteristics of the household clusters are summarised in Table 3.

To assess the relationship between respondents' perceptions of forest cover change against their livelihood typologies, we used a chi-squared test. Age was categorised with those below 30 years grouped in one category, while those above 30 years are in age groups in 10-year increments. This is to elaborate perceptions of those that have lived longer than the study period (30 years), and compare them with the younger respondents. A chi-squared test of the relationship between age and perception of forest cover change was computed. All $\mathrm{p}<0.05$ was considered significant.

\section{Results}

\subsection{Demographic characteristics of sampled households}

Aggregate descriptive statistics of all continuous variables gathered during fieldwork are summarised in SI 1. It is of interest to report the demographic characteristics of the households sampled, and to consider the pattern in relation to census data. A population pyramid for all members of the sampled households, both the nuclear and extended families, is shown in Figure 4. The pyramid is typical of a rapidly growing population with the majority household population consisting of a large number of children below the age of 20, and very few elderly people, although there are some marked differences in the bins of age groups under 16 (Figure 3).

Figure 3 Scree plot showing the contribution of each PC to the total variation in the data-set

Figure 4 Population pyramid of surveyed households (includes all members living in the household at the time of the survey; age in years)

\section{Figure 5 Dendrogram of household categorisation using Ward's method}

\section{Table 3 Summary of Cluster Characteristics}

\subsection{Agro-Ecological Zone-Level Cluster Composition}

Households in the forested regions (Budongo and Bugoma AEZs) mostly belonged to cluster 2 (low income mixed farming households), accounting for $60.7 \%$ and $45.2 \%$, of the total surveyed households in Biiso and Busingiro parishes in Budongo AEZ, respectively; and 34.7\%, 57.1\% and $25.4 \%$ of households surveyed in Bubogo, Igwanjura and Kyangwali (Bugoma AEZ), respectively. In Budongo AEZ however, Kibwona parish is dominated by cluster 3 (low income crop specialist households), where households are involved in an out-grower sugar-cane production scheme alongside other food crops, while Nyabyeya has a more mixed composition although dominated by cluster 1 (moderate income, livestock specialist households) (Figure 6). Within the sampled 
households, there is a lack of cluster 7 households (richest, "elite" mixed farming and trading-based households) in all the parishes in Budongo and Bugoma AEZs except for Bubogo and Igwanjura, and even then, these have a low representation, at $2.0 \%$ and $1.8 \%$ respectively.

\section{Figure 6 Cluster membership per Agro-Ecological Zone; clusters computed from 17 principal components using Ward's method}

As expected, the peri-urban AEZ is dominated by cluster 4 households (limited cultivation households with moderate off-farm income), accounting for $22.4 \%, 30.6 \%$ and $41.1 \%$ of the surveyed households in Westernward (Masindi), Southernward (Masindi) and Mparo (Hoima) respectively. Kasingo (Hoima) is however dominated by cluster 2 households accounting for $25.9 \%$ of the total surveyed households. The peri-urban AEZ also has the highest percentage of cluster 7 households (richest, "elite" mixed farming and trading-based households) compared to the other AEZs accounting for $12.1 \%, 10.2 \%$ and $14.3 \%$ in Westernward (Masindi), Southernward (Masindi) and Mparo (Hoima) respectively. Kasingo parish has the smallest percentage (only 3.7\%) of cluster 7 households amongst the peri-urban AEZ parishes.

In the semi-arid AEZ, however, cluster 2 (low income mixed farming households) is most dominant, accounting for $32.8 \%$ and $50.0 \%$ of the total number of surveyed households in Kisansya and Kigwera respectively. There is also a mixture of cluster 4 (limited cultivation households with moderate off-farm income) particularly in Kisansya (27.6\%), where households are involved in fishing in Lake Albert, and cluster 1 (moderate income, livestock specialist households) mostly in Kigwera (23.2\%) households that are involved in free range grazing of cattle and goats.

The other clusters are in varying proportions across the different parishes in the four AEZs, indicating marked variation in the household livelihood characteristics at the parish-scale.

\subsection{Local People's Perceptions of Forest Cover Patterns: A Comparison with Remote Sensing Analyses}

While some respondents declined to answer the question about trends in forest cover (between $15 \%$ and $31 \%$ in the seven parishes), and even fewer were "don't knows" (0\% to 6\%), the majority considered forest cover to have declined (between 56\% and 77\%). However, a sizeable minority (between 1\% and 21\%) considered forest cover to have increased. The sample around Bugoma AEZ was more consistent in the perceptions of a forest decline, although more mixed responses are recorded in parishes around Budongo (Figures 7 and 8d). Possible reasons for the variation in the perception of forest change are considered in the following sections.

A comparison of the respondents' responses to the remote sensing analyses of forest cover change shows agreement in the data, generally indicating forest loss in regions around Budongo and Bugoma AEZs (Figure 8a). For instance, in Nyabyeya parish (Budongo AEZ) there is a mixture of responses on forest cover patterns, and this corresponds to mixed patterns of forest loss/gain/stability (computed from Landsat imagery) within the landscape (Figure 8a, b, c). This is similar to other parishes around Budongo AEZ, although forest cover patterns in Biiso and Busingiro parishes appear to be less well perceived when compared with the remote sensing analyses. This is related to the relatively smaller forest cover in Biiso, while a large percentage of the forest area in Busingiro parish that has persisted lies under the protected region (see also Figure 2). Otherwise, all forest cover outside the protected region was lost.

Around Bugoma AEZ, on the other hand, the responses are highly consistent with the remote sensing results. The largest part of each of the parishes lies outside the protected area. The largest percentage of respondents in Bubogo, Igwanjura and Kyangwali parishes highlighted that forest cover had mostly declined, which is consistent with the remote sensing results (Figure 8a, b, and c).

Figure 7 Summary of perceptions of households on forest cover change in the last 30 years in the parishes around Budongo and Bugoma forests

Figure 8 Comparison of responses on perceived forest cover changes with results from remote sensing analysis at parish level

\subsection{Perceptions of Forest Cover Patterns by Respondent's Age}


While there is a general agreement that forest cover has declined in the last 30 years, younger people (aged 15-29) who comprise the majority of the respondents are more likely to think of the forest as declining compared to the older categories except in Biiso where people aged $60+$ are more inclined to believe it $\left(\mathrm{X}^{2}=237.6, \mathrm{df}=66, \mathrm{p}=0.000\right)$. The other response categories are mixed amongst all the age groups where varying perceptions were recorded, especially in parishes around Budongo (Figure 9).

Overall, the average age of the respondents is greater than the length of the period under investigation (30-years) in all surveyed parishes, at 39 years $(95 \%$ Confidence Interval, henceforth "CI": $37.3,40.6)$, and this varied by parish although not significantly. At parish level, on average, the oldest respondents in decreasing order around Budongo are: in Biiso at 44.5 years (95\% CI: 39.8, 49.2), Busingiro at 38.8 years (95\% CI: 35.1, 42.4), Nyabyeya at 38.2 years (95\% CI: $34.2,42.1$ ), and Kibwona at 37.1 years (95\% CI: 32.6, 41.5). Around Bugoma forest, the oldest respondents were in Bubogo at 39.0 years $(95 \%$ CI: 33.1, 44.9), followed by Kyangwali at 38.5 years (95\% CI: 34.5, $42.5)$, and Igwanjura at 38.2 years (95\% CI: 33.6, 42.9).

\section{Figure 9 Perceptions of forest cover change in the last 30 years in parishes around Budongo and Bugoma by age group}

\subsection{Perceptions of Forest Cover Patterns by Livelihood Typology}

There is a strong signal that livelihood typologies are significantly $\left(X^{2}=623.4, d f=4, p=0.000\right)$ related to perceptions on forest change : respondents who perceived forest cover as having declined and those that provided no response mostly belonged to cluster 2 (low income mixed farming households), although this could be because this is the dominant livelihood typology around Budongo and Bugoma forests. Cluster 7 households (richest "elite" mixed farming and trading-based households) are generally lacking in this part of the landscape, but a handful of respondents who belonged to this group perceived forest cover as either having declined or provided no response (Figure 10). The other typologies are in rather small proportions.

\section{Discussion}

There are several issues that this analysis could highlight, but discussion in the following sections is structured to address the research questions posed in section 1. We first address the important variables driving the household classification, and the proportions of different clusters in each Agro-Ecological Zone (AEZ). Then we explore potential hypotheses on the spatial distribution of household types relative to the $4 \mathrm{AEZs}$, and note possible implications of this for deforestation.

\subsection{Key Discriminators of Livelihood Characteristics in the Landscape}

The application of a Principal Components Analysis (PCA) to reduce redundancy in the large set of field data gathered was successful: 83 original variables were compressed to 22 principal components accounting for $75 \%$ of the variance. The PCA particularly highlights variable groupings that are the most important discriminators of dissimilarity in the entire data. Significant variation was related to agricultural time input (PC1), on-farm income particularly from cropping activities (PC2), livestock husbandry (PC3), demographic characteristics (PC4), agricultural extension activities (PC5), and cultivation labour input (PC6). These are discussed in turn.

The backbone of the rural economy has its basis in agriculture (Fan and Zhang 2008): this is the main source of food, with the surplus sold for income to purchase basic needs (e.g. salt, clothing, pay children's school fees, medical expenses, etc). Depending on the Agro-Ecological Zone, households spend varying amounts of time and labour on agricultural activities (e.g. opening up agricultural land, weeding, harvesting, postharvest handling, etc). However, households in the periurban and semi-arid AEZs tend to spend less time on agricultural activities. The majority of households still use rudimentary low-input technologies, and therefore spend more or less time on agricultural activities based on the amount of labour, time (season), tools available, and farm size, among other factors. These activities are routine during both the dry and wet seasons, and therefore are a priority, depending on the development stage of the cultivated crops. This is shown by the positive correlation between the cultivation time variables. 
The largest contribution to household on-farm income is from crop sales. Households, particularly in cluster 3, obtain relatively higher crop yields which boosts their income from sales from the surplus. Households in Kibwona parish present a peculiar case, as some of those that participated in the survey are part of a sugar-cane out-grower scheme. Their total yields are therefore considerably boosted by their involvement in the sugar industry, although their yields from other crops are similar to those in the other parishes in Budongo AEZ. Low yields in cluster 7 households, who have the largest farms and better access to technology, could be related to low labour input (related to the small household size).

Livestock husbandry is relatively common in this region, although more pronounced amongst households in the peri-urban and semi-arid AEZs. They typically keep small ruminants (goats and sheep) and pigs, and very few cattle. Livestock, particularly cattle, in the semi-arid AEZ (and other parts of the region) are viewed as a wealth status symbol in society. These households (mainly in the semi-arid AEZs) keep moderate animal numbers, but of low quality (largely malnourished due to limited and seasonal availability of food and water). Small ruminants are preferred to larger animals due to housing space limitations, although most of the grazing is of the free range type: animals are allowed to roam on large communal fields under supervision of a member of the household (especially in the semi-arid AEZ). In places where there is a mixture of cropping activities and settlements, households opt for the tethering grazing method, which controls livestock movement and avoids crop raiding.

Household demographic characteristics are generally similar, with medium to large household sizes that include both nuclear and extended families. The population pyramid shows a very large percentage of the population is under 20 years of age, an indicator of a rapidly growing population. The population growth rate in the landscape is one of the highest in the world, estimated at nearly $4 \%$ per annum (Bongaarts 2009). There are some marked variations in the bins for males and females under the age of 16 , and the causes of this are not obvious. This could be due to sampling biases where households with more males under the age of 10 are included, or to mortality rate differences in children by gender; or perhaps some issues regarding age reporting. The level of education is generally low, the majority having only attained primary education (between primary 4 and 7). This does not vary much across AEZs, except for a few elite households living mostly in peri-urban areas (with members having education up to university level). This could relate to the distribution of schools in rural areas, where there are fewer per parish compared to the peri-urban areas, as well as the challenge of agricultural labour being provided by school-age children. Further research is required to understand the causes of early drop-out from education.

Participation in agricultural extension activities stands out as a key variable. Agricultural extension activities include trainings in particular agronomic practices, pest and disease control, appropriate livestock management practices, amongst others. Some households have limited access to agricultural extension services and have stated that they are not visited by the government extension, and agricultural advising officers. Local governments hire extension officers at subcounty level but these are too large to be managed by one staff member who often has poor facilities due to budget constraints. Households that attend extension services to the greatest degree are those in cluster 8 , although some activity is recorded in clusters $5,6,7$, and 9 . These are mostly in rural areas which take part in agricultural production.

Due to limiting factors on production in the rural areas, households diversify with various enterprises for their survival. A variety of the activities are found in the mid-table of the PCA matrix, including trading goods and merchandise in shops, selling agricultural produce from home, or in village markets; however, factors such as livestock income, quantity of forest products used (particularly poles and timber) and off-farm income contribute the least to variation in the data. Households typically do not depend on livestock products; besides livestock numbers are generally too low to enable them to dispose of any for income. Recorded sales during the data gathering period were only a handful. Moreover, few households are however involved in off-farm employment both in the public and private sectors. In the private sector, households predominantly from the semi-arid AEZ, close to Lake Albert, engage in fishing to supplement their incomes. Other jobs include providing informal labour to the sugar-cane industry especially by households in Nyabyeya and Kibwona parishes around Budongo AEZ. While it would be expected 
that the use of forest products (poles and timber) would be a good discriminator of those households close to natural forest, this surprisingly ranks low in the PCA model. It may be that poles and timber are poor indicators of dependence on forest products - but these are products that were relatively easy to quantify (as they have fairly easy dimensions to measure, making volumes consumed easy to compute), unlike those such as medicinal plants, wild fruits, papyrus reeds among others. The data show that households living near forests do access these products (poles and timber), but in relatively small quantities. It is difficult to judge if the correct quantities were reported, and if these products were a source of income, or if they were only used in construction of housing; the latter may be the case, meaning that relatively few poles and timber products would be required.

\subsection{Agro-Ecological Zone Cluster Composition: Examining Spatial Patterns and Livelihood Adaptation}

The data show that households that live around forested regions in Budongo and Bugoma AEZs are mostly low-income earners (belong to cluster 2: low income mixed farming households) and are more dependent on forest products for their livelihoods than their peri-urban and semi-arid AEZ situated counterparts. They are caught up in what is arguably a vicious cycle of poverty that contributes to environmental degradation (de Sherbinin et al. 2008). They have relatively large household sizes, and as they struggle to sustain them by providing the basic needs (food, shelter, clothing, education, medication, etc), with the limited on-farm and off-farm income, they seek extra livelihood from their environment. Poverty leads to high fertility due to demand for farm labour, ('insurance births' owing to high infant mortality): high fertility then contributes to large households which further increases demands for food and resources from an essentially static resource base (de Sherbinin et al. 2008). The deforestation patterns identified in Twongyirwe et al. (2015) may to some extent be explained by this, except perhaps in regions where commercial cultivation of sugar-cane, and illegal large-scale logging are key forest loss drivers. Studies have shown that forest dependent people are poorer, live close to the forest, and have lower livestock and crop income (de Sherbinin et al. 2008; Tesfaye et al. 2011).

Unlike the other parishes in the Budongo and Bugoma AEZs, Kibwona and Nyabyeya (both in Budongo AEZ) show striking differences. Kibwona is dominated by cluster 3 households (low income crop specialist households), which are mostly dependent on sugarcane production as part of the out-grower scheme alongside other food crops. The out-grower scheme is a franchise-based program where farmers are given start-up capital in kind (e.g. the company clears land, does the planting, weeding, pest control, application of fertiliser, and harvesting) provided they offer their land for sugar-cane production in a contract of often more than 5 years (at least 3 ratoon-harvests ${ }^{1}$ : estimates from a key informant). The investment costs by Kinyara Sugar Works are then deducted from the final annual payments made to the farmer after buying the sugar-cane from them. While further research is required to understand if the sugar-cane industry is improving the socioeconomic status of participating households, the data show that they on average remain low income earners. This is possibly due to the fact that the payments are one-offs, made on an annual basis. Because the farmers offer up their land for commercial sugar-cane production, they are then left with rather small pieces on which they grow their food. Households in Nyabyeya parish thrive mostly on livestock husbandry. This may be associated with the Budongo community-based conservation project that provided goats to households surrounding Budongo forest as a way to boost their household incomes as an incentive to co-manage and protect the forest (information from a key informant based at the National Forest Authority). In general, households around the protected forest blocks diversify into several activities to boost their livelihoods as indicated by the mixed cluster composition, although the tendency for them to be poorer than those in the peri-

\footnotetext{
${ }^{1}$ Sugarcane is a ratooning crop, where new shoots spring from the stem and mature in a period of about 1 year. Once the mature sugarcane is harvested, new shoots sprout from the underground stem without having to go through the entire clearing, and planting process. Fertiliser application and weeding are the main agronomic practices undertaken during the growing season. When 3 ratoons are harvested, land is sometimes re-cleared, to prepare for a new planting campaign.
} 
urban areas is higher. There is, for instance, a lack of cluster 7 households (the richest, "elite" mixed farming and trading-based households) in both Budongo and Bugoma AEZs except for Bubogo and Igwanjura parishes which have a small number of cluster 7 households.

Unsurprisingly, the peri-urban AEZ is dominated by cluster 4 households (limited cultivation households with moderate off-farm income). Typically, urban dwellers are less involved in crop cultivation to earn a living, but more in off-farm formal and odd jobs. They own the smallest farm sizes, and invest the least time and labour in agricultural production. They purchase most of their food from local markets which source it from more rural areas. Additionally, they have a larger number of cluster 7 households (richest, "elite" mixed farming and trading-based households) compared to other AEZs. This could be related to the availability of social services (e.g. schools, markets) closer to them than the rural counterparts. Kasingo however, has dissimilar characteristics from the peri-urban AEZs, and is more similar to the rural AEZs, with the highest number of households belonging to cluster 2 (low-income mixed farming households). While Kasingo is within Hoima town council, the surveyed households live in the suburbs, and have more rural livelihood tendencies with space to engage in small-scale agriculture (mixed crop and animal husbandry).

The semi-arid AEZ livelihood dynamics are mixed; similar to Budongo and Bugoma AEZs, cluster 2 households (low-income mixed farming households) are dominant. The majority of the households are typically poor, and although they lack access to the natural forests, their livelihoods are diversified. This region is mostly dry and receives dry monsoon winds from the East African coast which essentially restricts cropping to those crops that can bear long stress periods (e.g. cassava and maize). The striking pattern of homogeneity in households along the transects (e.g. cluster 4 and 2 households in Kigwera) is corroborated by a study that found that although settlements are scattered, where there is clustering, such groups belong to the same ancestry (SNV 2012). These families also own or rent land in Ngwedo village (see Figure 1 for location) where they have gardens mainly for subsistence farming. Cluster 4 households (limited-cultivation households with moderate off-farm income), particularly in Kisansya parish, are involved in fishing in Lake Albert to supplement their incomes while cluster 1 households (moderate-income, livestock specialist households), especially those in Kigwera parish, are involved in free range grazing of cattle and goats. The customary land tenure system is one that favours free-range grazing, but is a disincentive to cultivation even though the soils and climate might be able to support dry-land crops (SNV 2012). Over-grazing is common, and often leaves the land bare, especially in the dry season (observed during fieldwork), and the stocking densities are reportedly high among a few migrant cattle farming settlers referred to as "Balaalo" (SNV 2012). From the study by SNV (2012), overgrazing was strongly linked to the migrants. On the contrary, the residents travel $10-15 \mathrm{~km}$ away to cultivable areas each season in a migratory manner; where some family members involved in crop production camp in Ngwedo until the crops are grown and return to Kisansya and Kigwera (surveyed parishes) to be part of the social life of the larger family.

\subsection{Local People's Perceptions on Forest Cover Change: Role of Age and Livelihood Typology}

There is wide agreement between remote sensing data analysis and local people's perceptions about forest cover change around Budongo and Bugoma; particularly, as is the case from remote sensing analysis, the majority of the respondents noted that forest cover has declined in regions outside the gazetted areas, but protection of Budongo and Bugoma is remarkably successful. The mixed responses in some parishes around Budongo may be related to the spatial pattern of forest cover where persistence, losses, and gains all occurred during different periods of the 30 years (see Twongyirwe et al., 2015), although the temporal trend is one that shows a decline overall. For instance, in Nyabyeya, the spatial difference map of 1985 and 2014 shows a mixture of large regions of forest gain and losses (see Figure 2a, 8a), and it is possible that the respondents could have perceived the spatial coverage near where they live to represent what was happening in the entire parish. It is unclear whether this could also be related to the 1999 forestry policy change. The policy involved dissolution of the forest department, and creation of four semi-autonomous forest bodies: National Forest Authority, Uganda Wildlife Authority, District Forest Services and Forest Sector Support Division (for details see Jagger 2008). 
Because of the illegal nature of some deforestation practices, the survey allowed an optional response to the question about the perceived trend in forest cover within the respondent's parish. The data show that overall, a relatively large number, 71 out of $375(18.9 \%)$ declined to provide a response, ranking second to those who perceived forest cover as having declined $(70.1 \%)$ in the last 30 years. The reasons for this remain rather speculative. It could be that they are involved in illegal harvesting of trees from the forest. A study elsewhere within the Albertine Rift region shows that people illegally dependent on natural resources are afraid of being reported to local authorities and can only provide responses under strong assurance of protection (Tumusiime et al., 2011). Although the data gathering team was highly trained on administering the questionnaire and in ethical issues related to the study, scepticism from the respondents could not be ruled out in spite of our assurance to protect them.

The data also show that age of the respondents is significantly related to their perception of forest cover patterns, where, although there was wide agreement on forest decline amongst all age groups, younger people were more likely to think of forest as having declined compared to the older ones. The survey included household heads who were below the age of 30 (but mostly above 20 years) as part of the design to minimise sampling bias provided they were on the transects taken during fieldwork. The data show that the parishes around Budongo and Bugoma have a similar age structure, and as shown by the population pyramid (Figure 4), the majority of the population in the landscape is young. This age structure is corroborated by the previous census (e.g. in the 2002 census, children below 18 years constituted $56 \%$ of the population while those below 15 constituted 49\%, in a total of 24.4 million, UBOS, 2002, although recent [2014] unpublished estimates show that the current total population is around 34.9 million). Aggregate statistics, however, show that the average age of the respondents is between 37.3 and 40.6 years, suggesting that a good number of the respondents are old enough to have experienced the period (30 years) under investigation. There is a high probability that they may have witnessed most or part of the forest cover change processes within their parishes. Perceptions on forest cover change are therefore likely to be shaped by what they have witnessed and by possible involvement in illegal activities for their livelihood. The disparity in the responses on perceptions of forest cover change by age group, particularly why younger people were more likely to think of forest cover as having declined requires further investigation.

Additionally, statistical evidence shows that livelihood typologies are significantly related to the perceptions of forest cover change. Poorer cluster 2 (low income mixed farming) households are generally located near the protected forests, Budongo and Bugoma. As pointed out by the household survey data and by key informant opinion, it is suggested that they supplement their livelihood from use of forest products. It is therefore not counterintuitive for most of them to think of forest cover as having declined in relation to their poverty status if they depend on forests for their livelihood.

In the light of these findings, our study shows that remote sensing data and local ecological knowledge should be used concurrently. Local ecological knowledge can be skewed by livelihood status and the age of the respondents, and can therefore not be taken as "unquestionable truth" when validating results from remote sensing. In spite of these limitations, it is unlikely that the wider picture of the on-ground situation is likely to be severely obscured if the sample size is reasonably large.

\section{Conclusions}

From the Principal Components Analysis (PCA), the data show that cultivation time budgets, onfarm income especially from cropping activities, livestock husbandry, and household demographic characteristics are among the major sources of variation in household livelihood socio-economic status; while the use of forest products (poles and timber), and off-farm income, are the least variable factors. The region is predominantly agrarian, with different crops suitable for different areas, and therefore time requirements for crop production turned out to be the main difference in the livelihood typologies. Varying crop yields and farm sizes contributed to the disparity in the onfarm incomes earned across the region. As a livelihood adaptation strategy, households kept varying numbers of livestock based on affordability, availability of grazing land, prestige, and time 
to look after the animals, among other factors. The region generally has large household sizes averaging between 6-10 members, and the population pyramid is typical of a rapidly growing population (which is likely to exert more pressure on the already constrained and fragmented resources, with implications on further future forest loss). The data show on the other hand that poles and timber are not widely used forest products amongst the surveyed households, and therefore, perhaps, a poor surrogate of forest product dependence. Households adjacent to the forests do, however, rely to some degree on other forest products such as firewood (this was quantified), and other non-quantified products (e.g. medicinal plants, bush meat, etc) reported in key informant interviews. As few members in the households are involved in off-farm activities, off-farm income is also a poor discriminator of the livelihood status.

The cluster analysis from this paper shows that cluster 2 (low-income mixed farming households) is dominant in the region, and is the category most common amongst rural households located in parishes around Budongo and Bugoma AEZs, as well as the semi-arid AEZ. Peri-urban households mostly belong to cluster 4 (limited-cultivation households with moderate off-farm income). Households adapt to livelihood constraints in the various AEZs by diversifying to different agricultural enterprises. For instance, many types of crop are grown on small plots within each season, often with intercropping, or further splitting the already small pieces of land to accommodate each crop. On average 3 to 4 different kinds of food crop are grown per household per season. The majority of the poor households live near the forests, and are dependent on forest products (other than poles and timber, as these are not clearly picked out in the data) to boost their livelihoods. In all AEZs, households keep livestock (although few) to boost their incomes (especially in a crisis), and for provision of milk. In the peri-urban AEZ, there is a mixture of offfarm employment, and some small-scale farming to support the livelihoods in those areas.

Further analyses and the implications of these results in the wider context of land use and deforestation are explored in the people's perceptions to forest cover change. However, in spite of the criticism regarding the subjective nature of a PCA and cluster analysis suitable for exploratory analyses (Vyas and Kumaranayake 2006), we argue that the results produced are meaningful and convincing. The PCA was able to compress a rather large data set (83 variables) into a few interpretable dimensions (22 components). The clusters constructed are appropriate as they have been able to meaningfully delineate the different livelihood characteristics in the four AEZs. Essentially, the data indicate that policy interventions targeting rural livelihood enhancement ought to be focused, emphasising more local-scale strategies.

In addition, there is strong agreement between data from remote sensing and local people on the trend of forest cover change in parishes around Budongo and Bugoma forest in the last 30 years. This agreement generally stresses that forest loss outside the protected forest is widespread but protection of the gazetted Budongo and Bugoma is successful with clear boundaries (defined using a combination of physical features; e.g. rivers, roads, and boundary markers) albeit with some illegal encroachment. Data from local informants is largely credible, although it needs to be interpreted against its specific context (as seen from mixed responses around Nyabyeya for instance) and corroborated with key informant sources (and available literature).

Lastly, there is statistical evidence that age and livelihood typologies are related to perceptions of forest cover change, although reasons for younger people thinking of forest cover as mostly having declined compared to the older ones remains a question for further research. Additionally, judging the influence of livelihood quality on perceptions of forest cover change is inherently complex. Although perceptions of local people on forest change and livelihood typologies have been shown to be statistically related, it could be that such parameters play a role in shaping views on environmental processes, but do not in themselves provide a complete understanding of human psychology. For instance, perceptions about forest decline might be age dependent (especially for the 30 year trend analysis), but other factors (e.g. education, wealth status, etc) may interact in a complex manner to shape perceptions and knowledge on forest cover change. Even though statistical analyses provide some hints, they may only explain a small portion of what we can see and comprehend. For these reasons, the analyses can only enable us to speculate on potential reasons for the interactions, and further studies are required to test the results. 


\section{SUPPLEMENTARY INFORMATION}

\section{SI 1 Questionnaire continuous variables - category, definition and computation}

\section{SI 2 Questionnaire categorical/qualitative variables}

\section{SI 3 Quantitative Methods}

The large amounts of data gathered for this research require robust statistical analytical techniques to unearth intricate structures. Principle Components Analysis (PCA) and Cluster Analysis (CA), often used in rural sociology (e.g. Chilongo 2014; Goswami et al. 2014; Mutoko et al. 2014), were employed in this investigation.

\section{(a) Principal Components Analysis}

In simplest terms, a PCA is a dimension reduction technique that condenses the total number of original variables to a smaller set of meaningful "new variables" which are scores or loadings of each original element onto the new dimensional space. The selected principle components are then used in a cluster analysis.

In a high-dimensional data-set with multiple response $(\mathrm{y})$ and predictor $(\mathrm{x})$ variables, Principal Components Analysis (PCA) is a well-established approach for mining the 'important' response variables. PCA is a form of multiple linear regression (see equation below: Vyas and Kumaranayake 2006), where lines (vectors) are drawn through a multi-dimensional data-set such that the sum of squared distances from the line to all points in the data is minimized (Bell et al. 2015).

$$
\begin{gathered}
\mathrm{PC}_{1}=\mathrm{a}_{11} X_{1}+\mathrm{a}_{12} X_{2}+\ldots+\mathrm{a}_{1 n} X_{n} \\
\dot{\mathrm{PC}_{\mathrm{m}}}=\mathrm{a}_{m 1} X_{1}+\mathrm{a}_{m 2} X_{2}+\ldots+\mathrm{a}_{m n} X_{\mathrm{n}}
\end{gathered}
$$

Where $\mathrm{a}_{m n}$ represents the weight of the $m$ th principal component (PC) and the $n^{\text {th }}$ variable (Vyas and Kumaranayake 2006). The first vector becomes the first Principal Component (PC), with the projection of the data onto this component explaining a 'large' fraction of the overall variation in the data. A second vector (second PC) is orthogonal to, and thus uncorrelated with the first, and is constructed in a similar way. This is repeated to generate $n$ orthogonal vectors, where $n$ is equivalent to the number of input variables. As successive components are computed, they explain additional but lesser variation; the $n^{\text {th }}$ PC explains a greater fraction of the data than the $(n+1)^{\text {th }}$.

The set of PCs is a rotation of the original multi-dimensional space so that all original variables have a 'loading' along each PC, with high loadings indicating high correlation between the original variable and the PC, essentially reducing the effective variable set by removing redundancy (Bell et al. 2015). To define what each PC means, we identify the original variables correlating most strongly with the components. Thus, PCA produces new variables (components) that can be given meanings in terms of the measurements in the original data-set; in which the variance is concentrated into fewer components; and through which redundancies in the original data-set are exposed, to provide opportunities to generate a simplified variable set.

The appropriateness of applying a PCA to the data (with 706 households, and 83 variables) was confirmed using two tests. Upon running the Kaiser-Maier-Olkin test (KMO) a solution of 0.78 was obtained (essentially a 'good' goodness-of-fit of the PCA model: $0.90+$ is often described as "marvellous", in the 0.80's as "meritorious", in the 0.70's as "middling", in the 0.60's as "mediocre", in the 0.50's as "miserable", and below 0.50 as "unacceptable": Holland 2013). Bartlett's sphericity test was significant $\left(X^{2}=98326.6, d f=3403, p=0.000\right)$. Bartlett's test of sphericity evaluates whether each sequential eigenvalue is significantly different from the remaining eigenvalues (Jackson 1993). If the data are overly correlated or independent, then a PCA may not be successful, hence the need for the KMO and Bartlett tests (Bidogeza et al. 2009). Categorical variables are generally not included in the Principal Components Analysis as scaling them produces meaningless results.

Prior to running the PCA, the data were standardised using z-scores. The key principle of matrix standardisation is to give every column a zero mean and unit standard deviation; this ensures that each variable has the same weighting in the analysis, particularly as the data are of different types 
and were recorded using different units (e.g. yields in kg, incomes in UGX, time budgets in hours, etc) (Vickers et al. 2003) that have significantly different absolute values.

Varimax rotation was used to produce components with loadings concentrated onto a smaller number of highly correlated variables than the initial PC set as an aid to interpretation (Bell et al. 2015). All components which account for at least $1.2 \%$ of total variation were retained. This decision was based on the following. From the 83 variables, which after standardisation (suppose each variable has a unit variance), each variable contributes, on average, $1.2 \%(100 / 83)$ to the total variation. Each PC that accounts for more than $1.2 \%$ of the total variation is therefore more important than the original variable. This effectively reduces the dimension of the data from 83 (original variables) to 22 (new variables, PCs in this case).

\section{(b) Cluster Analysis}

Cluster analysis is used, in this research, to identify socio-economic groups of households. Its classification outcomes are strictly dependent on the input variables used, and are often the scores of individual cases on the main (orthogonal) components derived from a PCA, rather than the values of correlated original variables (Ottaviani et al. 2003; Mayer et al. 2014). However, different clustering results are possible for different sets of input variables. As more variables are included, more distinctions can be made, for instance (in this case), between poor and very poor households (Vyas and Kumaranayake 2006).

There are two main clustering methods: agglomerative and divisive. The first of these involve agglomerative hierarchical clustering that produces small clusters of very similar items embedded within progressively larger clusters of increasingly dissimilar items. This approach is useful when we lack information on the data structure, and it is therefore difficult to predetermine the number of clusters into which to divide the data. Here, the approach is to build clusters that minimise within-group variance relative to between-group variance at each stage in the hierarchy. The second method is non-hierarchal classification (e.g. K-means clustering, that partitions n cases into $\mathrm{k}$ clusters) which are dependent on assuming the number of clusters a priori. This requires successive splitting of the original data. The solution can possibly also converge to a local optimum which is not actually consistent with some clear cluster structures in the data; this can be heavily influenced by the starting conditions for the algorithm, as with most optimisation problems.

An agglomerative hierarchical clustering was adopted in this research because it was not obvious how many household types might be revealed by the data. Starting with individual cases, the two most similar households were joined, then the next most similar, and so on (with the growing clusters replacing individual households in the agglomeration process). This continues until all households have been joined into a single large cluster, and the results are presented in a dendrogram. The criteria for clustering used the Euclidean distance between objects, and Ward's technique. Ward's method is widely used in the literature (Bidogeza et al. 2009; Chilongo 2014; Bell et al. 2015), and is based on minimising the within-group sum of squares, and produces compact well-defined clusters (Holland 2013). It is better than the nearest-neighbour or singlelinkage method which is based on the elements of two clusters that are most similar, and the farthest-neighbour or complete-linkage method based on the elements that are most dissimilar, and the median, group average, and centroid methods, as all these emphasise the central tendency of clusters and are less sensitive to outliers.

\subsubsection{Household Classification: Cluster Analysis}

Clustering is an exploratory data mining technique that attempts to group objects (in this case, households) of similar kind into classes or types (Ottaviani et al. 2003; Mayer et al. 2014). A cluster analysis is typically performed on a 2-dimensional data matrix involving cases and variables, where columns are variables and rows are cases (households). Often, the variables used are the 'significant' components defined by a prior PCA, and the number of components retained is based on 3 criteria. 1) The scree diagram, where a change in gradient distinguishes components with large from those with small eigen values (or variance contributions). 2) Kaiser's rule which states that eigenvalues should be greater than 1.3) The principle that the components selected should together explain at least $70-80 \%$ of the total variance (Jackson 1993; Bell et al. 2015). In this 
research, all of these rules were considered, and the first 17 PCs were retained, each of which has an eigenvalue $\geq 1$, leading to a total variance retained of $75.4 \%$.

Following PCA we constructed a dendrogram using Ward's method applied to the first 17 components (Figure 5).

\section{SI 4 Total variance accounted for by the first 22 Principal Components (rotated solution)}

This Table complements the scree diagram shown as Figure 3 in the text.

\section{SI 5 Rotated Component Matrix - loadings of variable per component}

This Table shows how the 83 original variables load onto the first 22 components, and the names given to the components.

\section{References}

Agrawal, A., 2007. Forests, Governance , and Sustainability: Common Property Theory and its Contributions. International Journal of the Commons, 1(1), pp.111-136.

Bell, A.R., Caviglia-Harris, J.L. \& Cak, A.D., 2015. Characterizing land-use change over space and time: applying principal components analysis in the Brazilian Legal Amazon. Journal of Land Use Science, (February 2015), pp.1-19. Available at: http://dx.doi.org/10.1080/1747423X.2013.832427.

Bidogeza, J.C. et al., 2009. A typology of farm households for the Umutara Province in Rwanda. Food Security, 1, pp.321-335.

Bogdanov, N., Meredith, D. \& Efstratoglou, S., 2008. A typology of rural areas in Serbia. Economic Annals, 53, pp.7-29.

Bongaarts, J., 2009. Human population growth and the demographic transition. Philosophical Transactions of the Royal Society B: Biological Sciences, 364(1532), pp.2985-2990.

Chalmers, N. \& Fabricius, C., 2007. Expert and Generalist Local Knowledge about Land-cover Change on South Africa's Wild Coast : Can Local Ecological Knowledge Add Value to Science? Ecology and Society, 12(1).

Chilongo, T., 2014. Livelihood strategies and forest reliance in Malawi. Forests, Trees and Livelihoods, 23(3), pp.188-210.

Costard, S. et al., 2009. Multivariate analysis of management and biosecurity practices in smallholder pig farms in Madagascar. Preventive Veterinary Medicine, 92, pp.199-209.

Dalle, P.S. et al., 2006. Integrating analyses of local land-use regulations, cultural perceptions and land-use / land cover data for assessing the success of community-based conservation. Forest Ecology and Management, 222, pp.370-383.

Dei, G.J.S., 1993. Indigenous African Knowledge Systems: Local Traditions of Sustainable Forestry. Singapore Journal of Tropical Geography, 14(1), pp.28-41.

Diwani, T.N. et al., 2013. Characterizing farming systems around Kakamega Forest, Western Kenya, for targeting soil fertility-enhancing technologies. Journal of Plant Nutrition and Soil Science, 176, pp.585-594.

Eilu, G., Hafashimana, D.L.N. \& Kasenene, J.M., 2004. Density and species diversity of trees in four tropical forests of the Albertine rift, western Uganda. Diversity and Distributions, 10, pp.303312.

Erzberger, C. \& Prein, G., 1997. Triangulation: validity and empirically-based hypothesis construction. Quality and Quantity, 31, pp.141-154.

Fan, S. \& Zhang, X., 2008. Public expenditure, growth and poverty reduction in rural Uganda. African Development Review, 20(3), pp.466-496. Available at: http://www.routledge.com/books/details/9780415603676/.

G.o.U, 2012. Uganda Vision 2040, Available at: http://npa.ug/wpcontent/themes/npatheme/documents/vision2040.pdf.

Hansen, M.C. et al., 2013. High-resolution global maps of 21st-century forest cover change. Science (New York, N.Y.), 342(6160), pp.850-3. Available at: http://www.ncbi.nlm.nih.gov/pubmed/24233722 [Accessed July 9, 2014]. 
Holland, S., 2013. Data Analysis in the Geosciences: Cluster Analysis. , p.8. Available at: http://strata.uga.edu/6370/lecturenotes/clusterAnalysis.html [Accessed March 4, 2015].

Jackson, D. A, 1993. Stopping rules in principal components analysis: a comparison of heuristical and statistical approaches. Ecology, 74(8), pp.2204-2214.

Jagger, P., 2008. Forest Incomes After Uganda's Forest Sector Reform: Are the Rural Poor Gaining? , (92), pp.1-35.

Lambin, E.F., 2002. Proximate Causes and Underlying Driving Forces of Tropical Deforestation. , 52(2), pp.143-150.

Lykke, a. M., 2000. Local perceptions of vegetation change and priorities for conservation of woody-savanna vegetation in Senegal. Journal of Environmental Management, 59(2), pp.107120. Available at: http://linkinghub.elsevier.com/retrieve/pii/S0301479700903360 [Accessed September 26, 2014].

Mayer, A., Winkler, R. \& Fry, L., 2014. Classification of watersheds into integrated social and biophysical indicators with clustering analysis. Ecological Indicators, 45, pp.340-349. Available at: http://dx.doi.org/10.1016/j.ecolind.2014.04.030.

McLennan, M.R. \& Hill, C.M., 2012. Troublesome neighbours: Changing attitudes towards chimpanzees (Pan troglodytes) in a human-dominated landscape in Uganda. Journal for Nature Conservation, 20(4), pp.219-227.

Ostrom, E. \& Nagendra, H., 2006. Insights on linking forests, trees, and people from the air, on the ground, and in the laboratory. Proceedings of the National Academy of Sciences of the United States of America, 103(51), pp.19224-31. Available at:

http://www.pubmedcentral.nih.gov/articlerender.fcgi?artid=1838564\&tool=pmcentrez\&ren dertype=abstract [Accessed July 10, 2014].

Ottaviani, D., Ji, L. \& Pastore, G., 2003. A multidimensional approach to understanding agroecosystems. A case study in Hubei Province, China. Agricultural Systems, 76, pp.207-225. Available at: $<$ Go to ISI $>$ ://000181537500011.

Owiunji, I. \& Plumptre, A.J., 1998. Bird communities in logged and unlogged compartments in Budongo Forest, Uganda. Forest Ecology and Management.

Pacini, G.C. et al., 2014. Combining Multi-Dimensional Scaling and Cluster Analysis To Describe the Diversity of Rural Households. Experimental Agriculture, 50, pp.376-397. Available at: http://www.journals.cambridge.org/abstract_S0014479713000495.

Plumptre, A.J. et al., 2007. The biodiversity of the Albertine Rift. Biological Conservation, 134(2), pp.178-194.

Sassen, M. et al., 2013. Complex contexts and dynamic drivers: Understanding four decades of forest loss and recovery in an East African protected area. Biological Conservation, 159(0), pp.257-268.

Seimon, A., 2013. Budongo-Sonso Daily Rainfall: 1993 - 2008.

Shackleton, R. et al., 2013. Deagrarianisation and Forest Revegetation in a Biodiversity Hotspot on the Wild Coast, South Africa. PLoS One, 8(10), pp.1-12.

Sheil, D. \& Wunder, S., 2002. The Value of Tropical Forest to Local Communities : Complications , Caveats , and Cautions. Conservation Ecology, 6(2).

De Sherbinin, A. et al., 2008. Rural Household Demographics, Livelihoods and the Environment. Global environmental change : human and policy dimensions, 18(1), pp.38-53. Available at: http://www.pubmedcentral.nih.gov/articlerender.fcgi?artid=2351958\&tool=pmcentrez\&ren dertype $=$ abstract $[$ Accessed September 1, 2014].

SNV, 2012. Agrarian Diagnosis Buliisa: summary on landscape and farming dynamics,

Southworth, J. \& Tucker, C., 2001. The Influence of Accessibility, Local Institutions, and Socioeconomic Factors on Forest Cover Change in the Mountains of Western Honduras. Mountain Research and Development, 21(3), pp.276-283. Available at: http://www.bioone.org/doi/abs/10.1659/02764741\%282001\%29021\%5B0276\%3ATIOALI\%5D2.0.C0\%3B2.

Sulieman, H.M. \& Ahmed, A.G.M., 2013. Monitoring changes in pastoral resources in eastern Sudan: A synthesis of remote sensing and local knowledge. Pastoralism, 3(1), pp.1-16.

Sunderlin, W.D. et al., 2005. Livelihoods, forests, and conservation in developing countries: An Overview. World Development, 33(9), pp.1383-1402. Available at: http://linkinghub.elsevier.com/retrieve/pii/S0305750X05000926 [Accessed July 16, 2014]. 
Tesfaye, Y. et al., 2011. Livelihood strategies and the role of forest income in participatory-managed forests of Dodola area in the bale highlands, southern Ethiopia. Forest Policy and Economics, 13(4), pp.258-265. Available at: http://dx.doi.org/10.1016/j.forpol.2011.01.002.

Tropek, R. et al., 2014. Comment on "High-resolution global maps of 21st-century forest cover change". Science (New York, N.Y.), 344(6187), p.981. Available at:

http://www.ncbi.nlm.nih.gov/pubmed/24876487 [Accessed July 19, 2014].

Tumusiime, D.M., Vedeld, P. \& Gombya-Ssembajjwe, W., 2011. Breaking the law? Illegal livelihoods from a Protected Area in Uganda. Forest Policy and Economics, 13(4), pp.273-283. Available at: http://linkinghub.elsevier.com/retrieve/pii/S1389934111000049 [Accessed July 10, 2014].

Twongyirwe, R. et al., 2011. Dynamics of forest cover conversion in and around Bwindi impenetrable forest, Southwestern Uganda. Journal of Applied Sciences and Environmental Management, 15(1), pp.189-195.

Twongyirwe, R. et al., 2015. Three decades of forest cover change in Uganda's Northern Albertine Rift Landscape. Land Use Policy, 49, pp.236-251. Available at: http://dx.doi.org/10.1016/j.landusepol.2015.07.013.

UBOS, 2002. 2002 Uganda Population and Housing Census Main Report,

UBOS, 2007. Uganda Demographic and Health Survey 2006, Macro International Inc. Calverton, Maryland, USA.

Vickers, D., Rees, P. \& Birkin, M., 2003. A new classification of UK Local Authorities using 2001 Census Key Statistics, Available at:

http://www.sasi.group.shef.ac.uk/area_classification/LA_Classification/03-3.pdf.

Vyas, S. \& Kumaranayake, L., 2006. Constructing socio-economic status indices: How to use principal components analysis. Health Policy and Planning, 21(October), pp.459-468. 


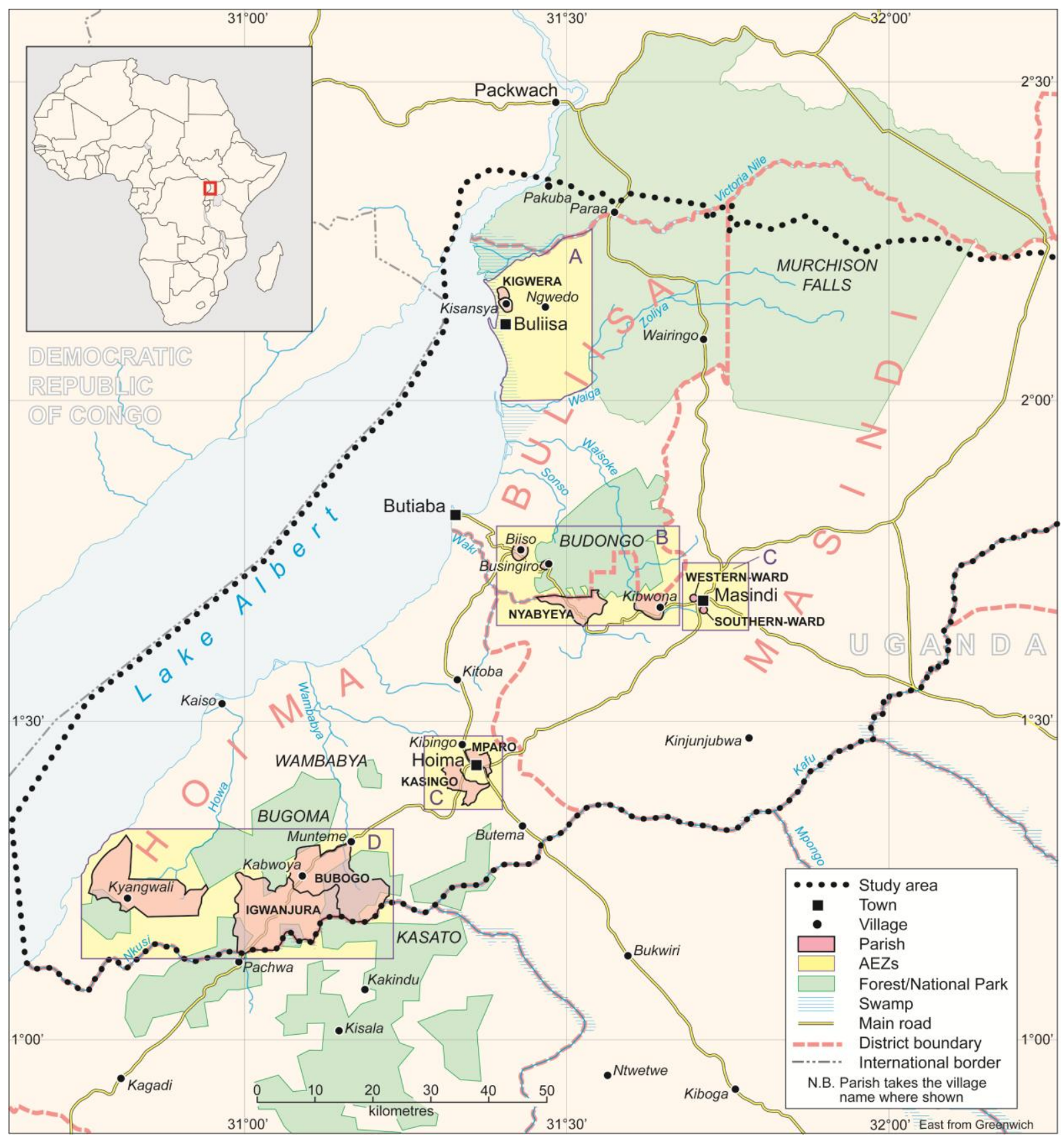

Figure 1 Map of study area showing the Agro-Ecological Zones (AEZs) where fieldwork was undertaken: A) Semi-arid zone, B) Budongo region, C) Peri-urban zone, D) Bugoma region 

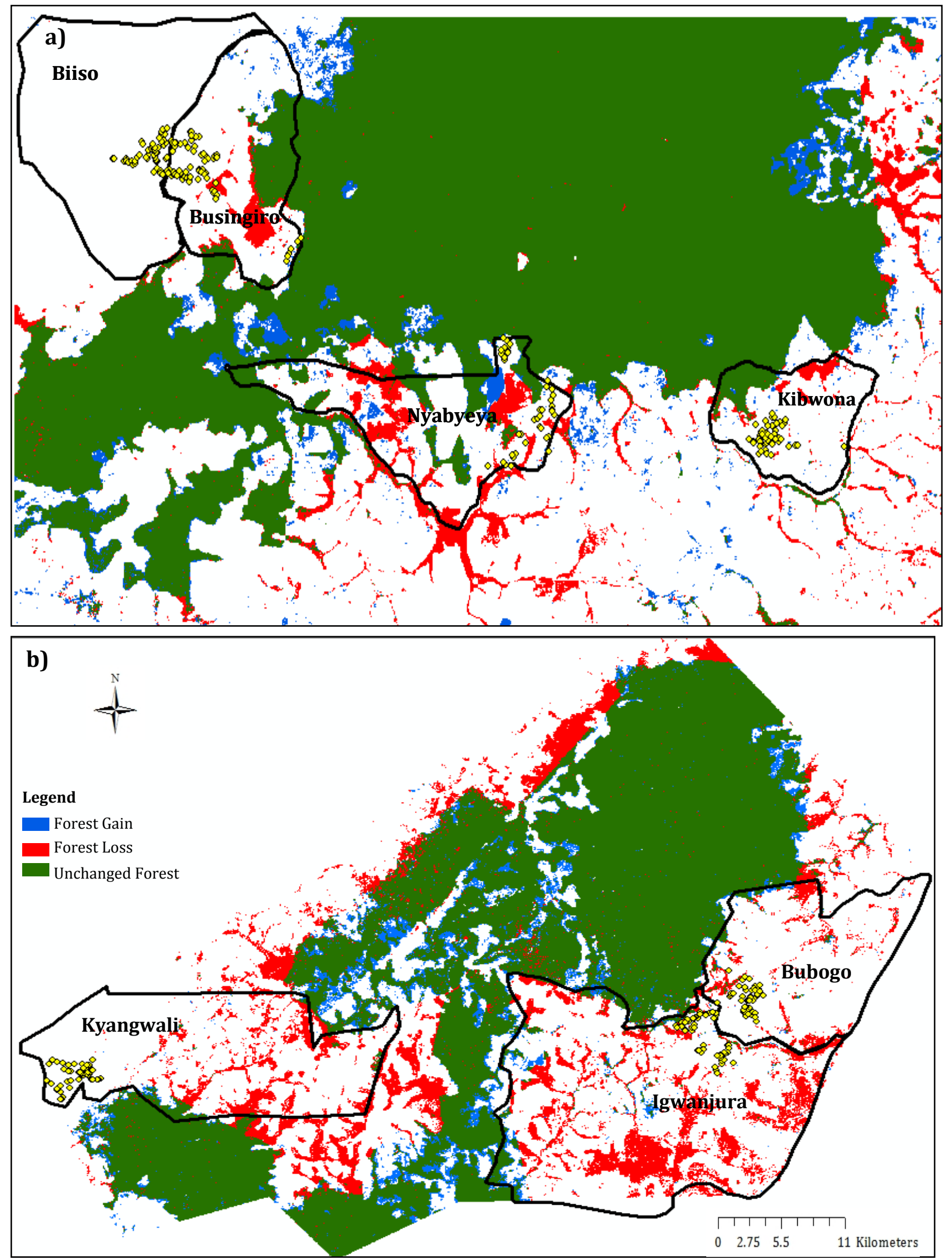

Figure 2 Surveyed parishes around a) Budongo, b) Bugoma Agro-Ecological Zones superimposed on the 1985-2014 forest change map (heavy lines indicate parish boundaries: surveyed households at the boundary of Biiso and Busingiro are separated based on field data. Surveyed households are shown in yellow; green represents unchanged forest, while red shows lost forest and blue represents forest gain over the 30 -year period) 


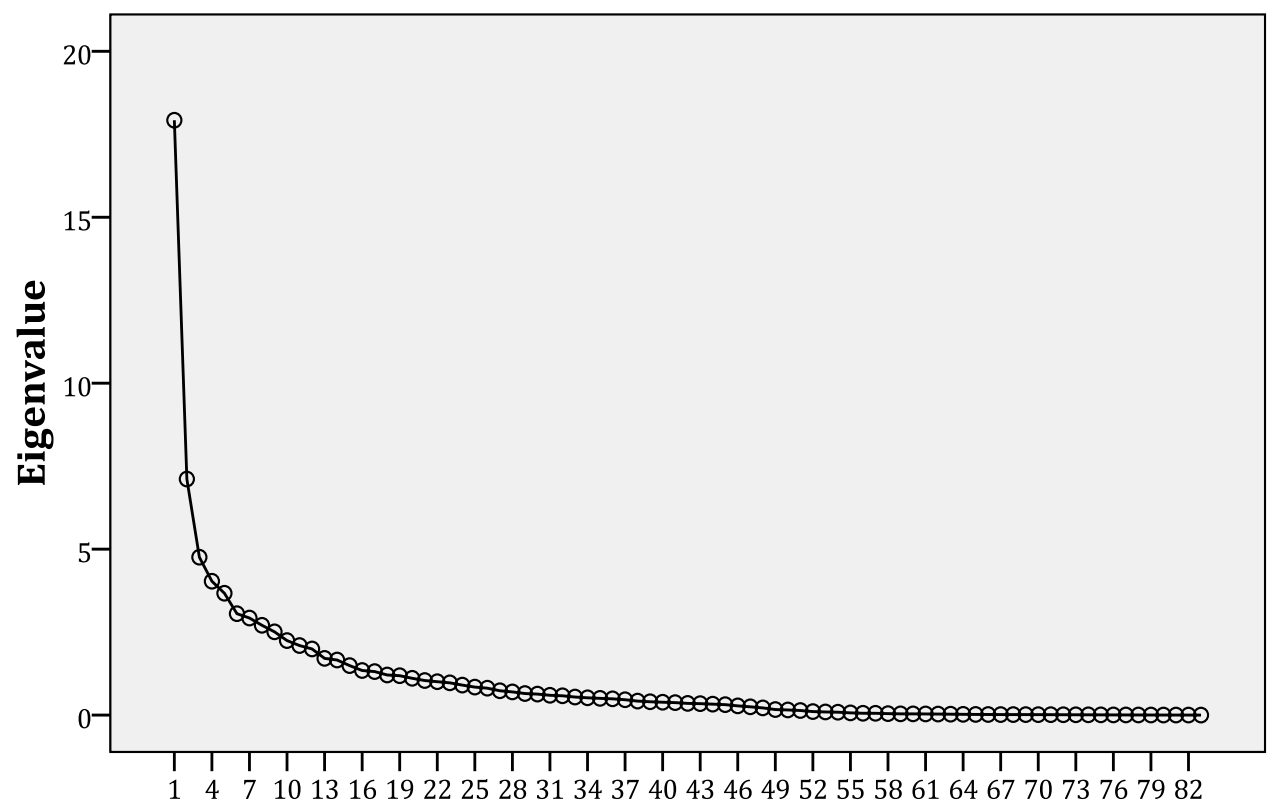

Figure 3 Scree plot showing the contribution of each PC to the total variation in the data-set

\section{Component Number}

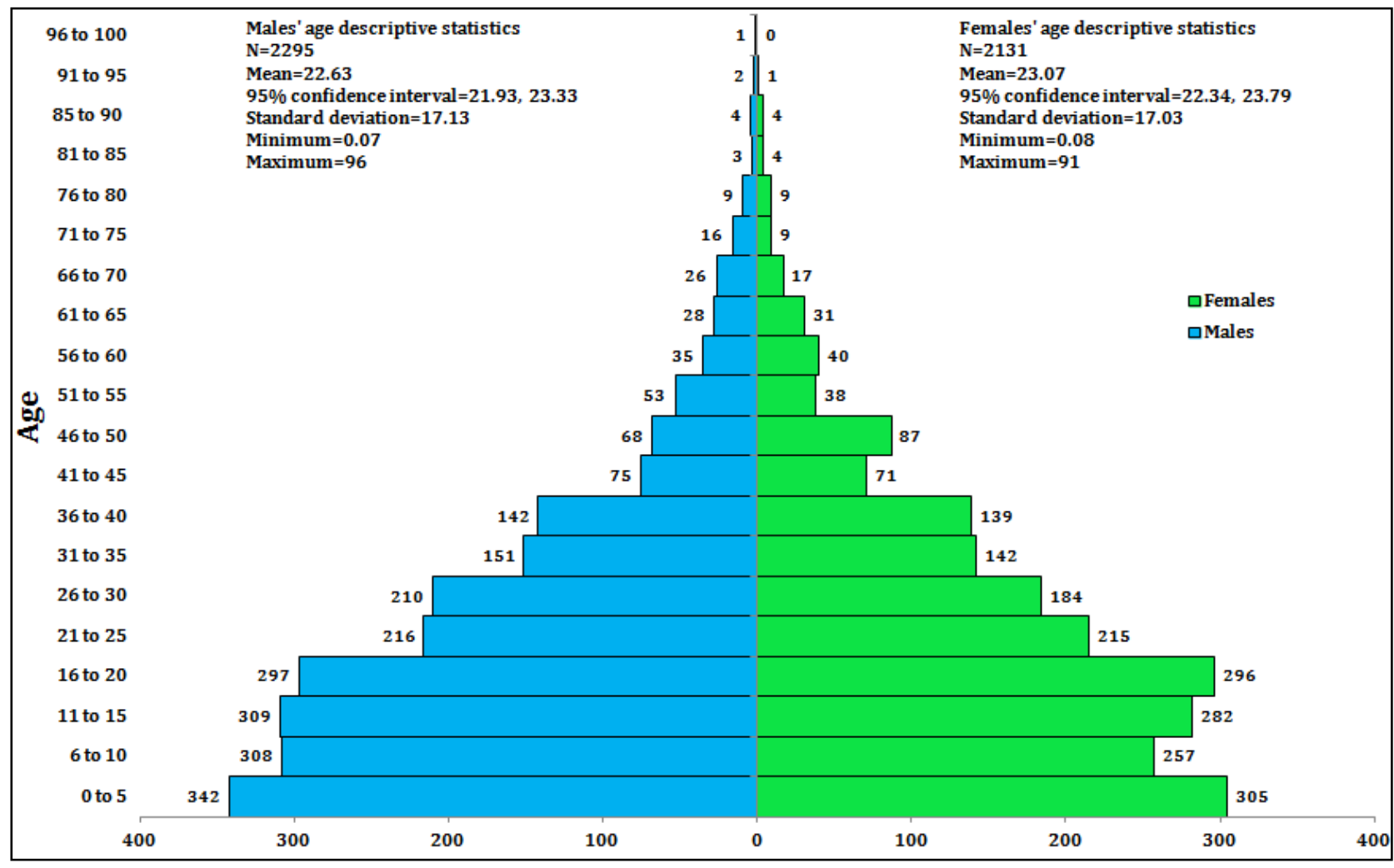

Figure 4 Population pyramid of surveyed households (includes all members living in the household at the time of the survey; age in years) 


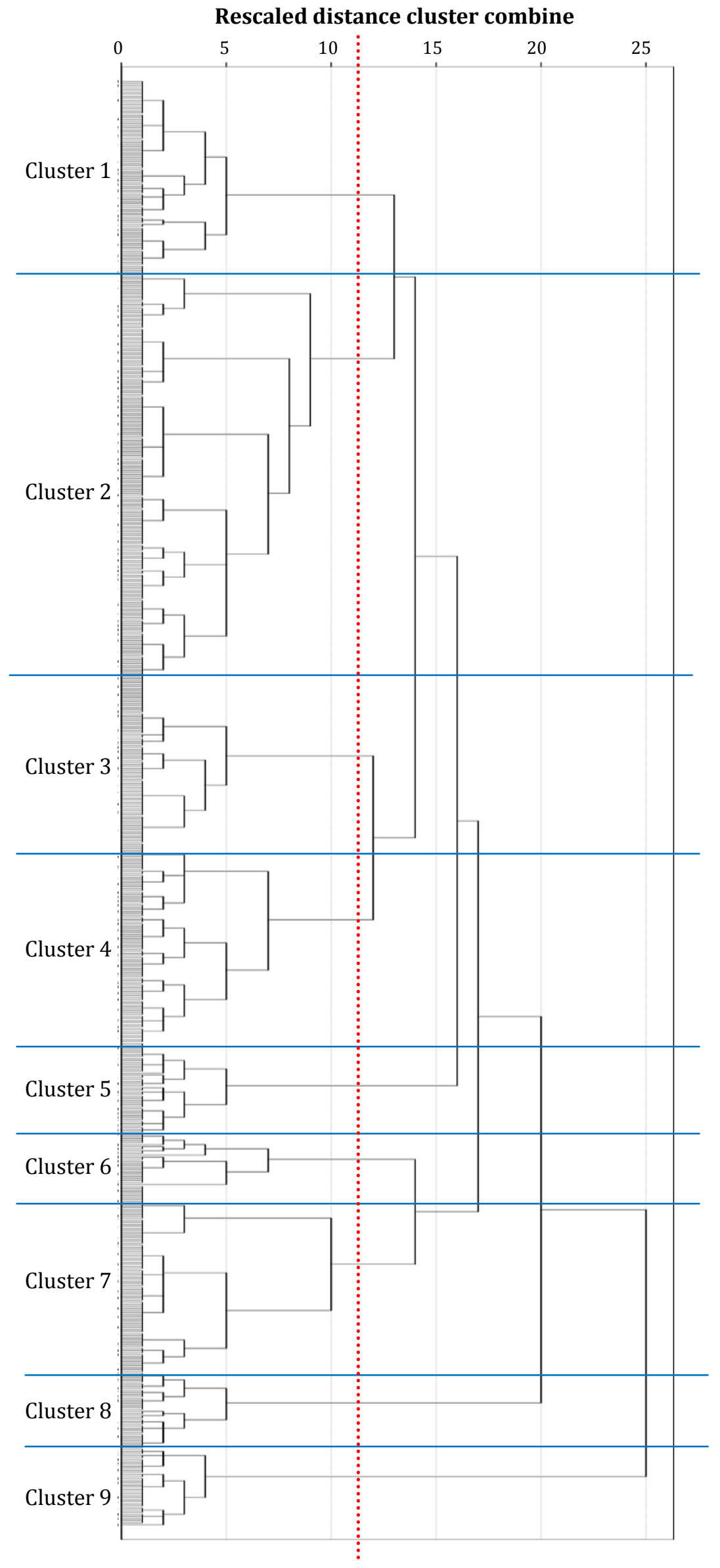

Figure 5 Dendrogram of household categorisation using Ward's method

9 clusters extracted from 17 principal components accounting for $75.4 \%$ of the total variation in the data. The blue lines indicate the cluster widths, while the dotted red line indicates the rescaled distance at which the clusters were delineated. Each long "cluster stem" cutting the red dotted line indicates that cluster grouping. 


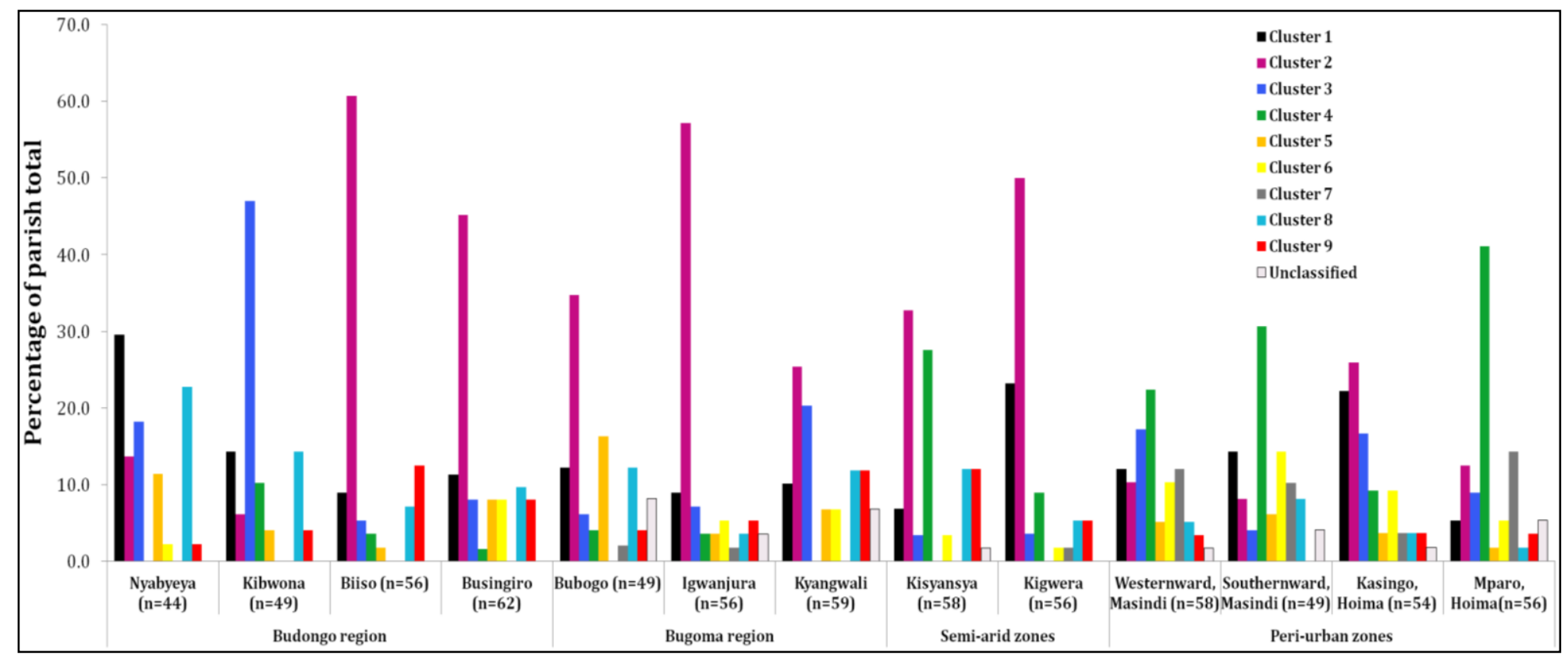

Figure 6 Cluster membership per Agro-Ecological Zone computed from 17 principal components using Ward's method 


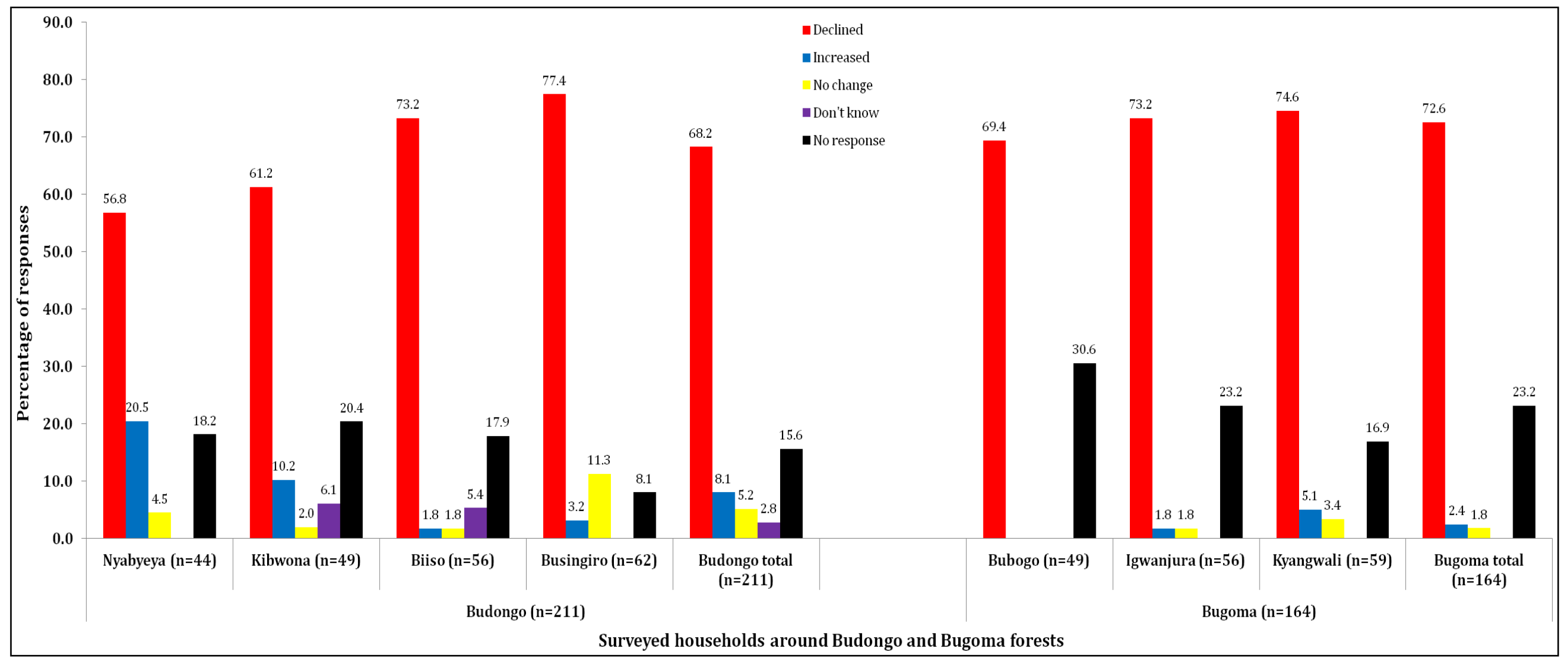

Figure 7 Summary of perceptions of households on forest cover change in the last 30 years in the parishes around Budongo and Bugoma forests

Generally, it was widely reported (by $70.1 \%$ of the total number of respondents: $n=375$ ) that forest cover had declined in the last 30 years. The responses varied in parishes around Budongo more than those around Bugoma. 
Figure 8 Comparison of responses on perceived forest cover changes with results from remote sensing analysis at parish level

(For the Landsat data, the change in forest area in 2014 is based on total forest area in 1985. The "don't know" and "no response" are obviously only present in the household survey response and not in the Landsat data, and therefore presented separately, Figure 8d)

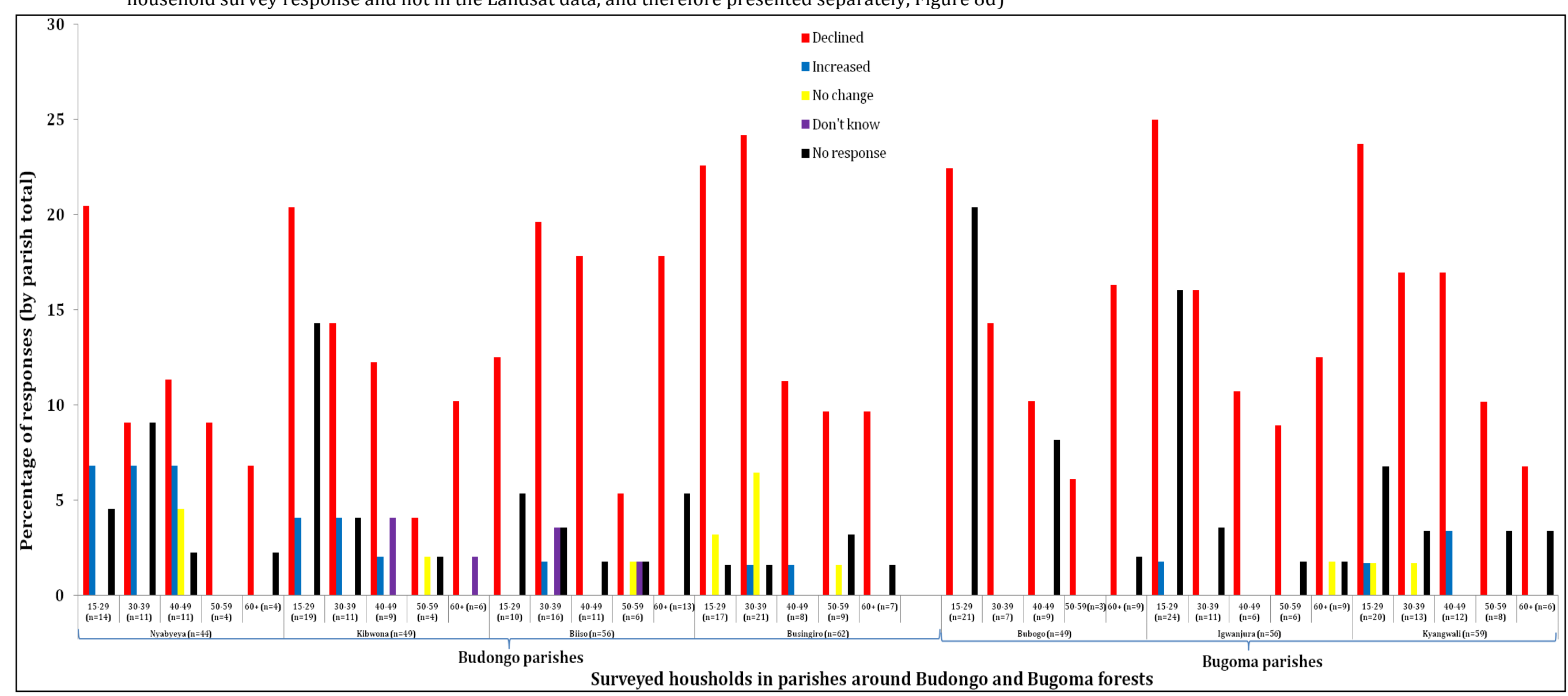

Figure 9 Perceptions of forest cover change in the last 30 years in parishes around Budongo and Bugoma by age group

While there is a general agreement that forest cover has declined in the last 30 years, younger people (ages 15-29) who comprise the majority of the respondents believed more that forest cover had declined compared to the older categories except in Biiso where more 60+ perceived forest cover as having declined. 


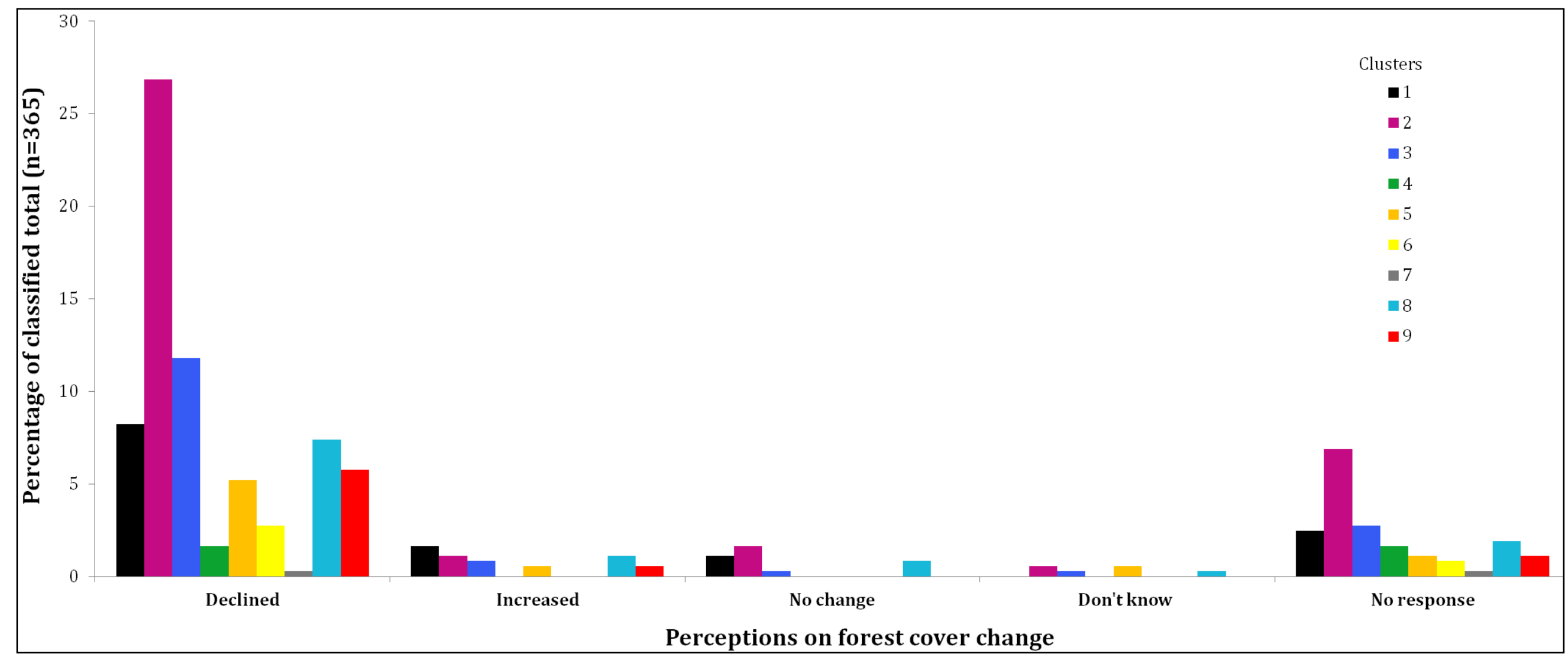

Figure 10 Relationship between perceptions on forest cover change and the household clusters

Households mostly belong to cluster 2 (low income mixed farming households); although statistical analysis using a chi-squared test indicates that perceptions on forest change are significantly related to the household livelihood typology (cluster). The 10 unclassified households around Budongo and Bugoma are excluded from this analysis. 
Table 1 Description and characteristics of the Agro-Ecological Zones

\begin{tabular}{|c|c|c|c|c|c|c|}
\hline $\begin{array}{l}\text { Agro- } \\
\text { Ecological } \\
\text { Zone (AEZ) }\end{array}$ & Major food crops & $\begin{array}{l}\text { Major cash } \\
\text { crops }\end{array}$ & $\begin{array}{l}\text { Mean } \\
\text { annual } \\
\text { rainfall } \\
(\mathrm{mm})^{\mathrm{a}}\end{array}$ & $\begin{array}{l}\text { Mean annual } \\
\text { temperature } \\
\left({ }^{\circ} \mathrm{C}\right)^{\mathrm{b}}\end{array}$ & $\begin{array}{l}\text { Elevation } \\
(\mathrm{m})^{c}\end{array}$ & Districts \\
\hline Budongo & $\begin{array}{l}\text { Cassava, maize, sweet } \\
\text { potatoes, beans }\end{array}$ & Sugarcane & $1397-1524$ & $\begin{array}{l}23-29(\min ), \\
29-32(\max )\end{array}$ & $914-1097$ & $\begin{array}{l}\text { Masindi and } \\
\text { Buliisa }\end{array}$ \\
\hline Bugoma & Cassava, maize, beans & Rice, tobacco & $1100-1350$ & $\begin{array}{l}16-18 \text { (min), } \\
28-29(\max )\end{array}$ & $1200-1350$ & Hoima \\
\hline Semi-arid & Cassava, beans & $\begin{array}{l}\text { Cassava, } \\
\text { cotton }\end{array}$ & $800-1000$ & $\begin{array}{l}22-25 \quad(\min ), \\
26-32(\max )\end{array}$ & $600-700$ & Buliisa \\
\hline Peri-urban & Cassava, maize, beans & Tobacco & $1000-1250$ & $\begin{array}{l}13-16 \quad(\min ), \\
18-30(\max )\end{array}$ & $1120-1150$ & $\begin{array}{l}\text { Hoima and } \\
\text { Masindi }\end{array}$ \\
\hline
\end{tabular}

Table 2 Sampled parishes in the four Agro-Ecological Zones

\begin{tabular}{|c|c|c|c|c|}
\hline Agro-Ecological Zone (AEZ) & Parish & $\begin{array}{l}\text { No. of villages in the } \\
\text { study parish }\end{array}$ & No. of respondents & Location (District) \\
\hline \multirow[t]{4}{*}{ Budongo } & Nyabyeya & 4 & 44 & Masindi \\
\hline & Kibwona & 3 & 49 & Masindi \\
\hline & Biiso & 4 & 56 & Buliisa \\
\hline & Busingiro & 3 & 62 & Buliisa \\
\hline \multirow[t]{3}{*}{ Bugoma } & Bubogo & 4 & 49 & Hoima \\
\hline & Igwanjura & 2 & 56 & Hoima \\
\hline & Kyangwali & 4 & 59 & Hoima \\
\hline \multirow[t]{2}{*}{ Semi-arid } & Kisansya & 2 & 58 & Buliisa \\
\hline & Kigwera & 2 & 56 & Buliisa \\
\hline \multirow[t]{4}{*}{ Peri-urban } & Westernward & 2 & 58 & Masindi \\
\hline & Southernward & 2 & 49 & Masindi \\
\hline & Kasingo & 3 & 54 & Hoima \\
\hline & Mparo & 3 & 56 & Hoima \\
\hline
\end{tabular}


1 Moderate time and labour investment in cultivation activities, low crop yields and low involvement in selling agricultural produce, moderate education level (albeit low), low involvement in extension activities, relatively low onfarm expenditure, low involvement in pest control activities, relatively small household size, small farm sizes and few agricultural implements, moderate amount of time on firewood gathering and firewood consumed, low amount of time spent on food preparation, low forest product use (poles), moderate amount of off-farm income, highest livestock husbandry involvement (large numbers of small ruminants), relatively high livestock incomes, mixed proportions of housing unit types and land ownership regimes

2 Relatively high involvement in cultivation activities, very low on-farm income and crop yields, lowest off-farm income, least involvement in extension meetings, least on-farm expenditure, not involved in pest control activities, relatively high amount of time spent on gathering firewood but least amount of total firewood used in a year, relatively small farm sizes and number of agricultural implements, moderate number of household members providing labour for agricultural activities, moderate education level (albeit low), moderate number of livestock, moderate amount of time spent on livestock husbandry, moderate household size and level of education, fetching water and cooking, low amount of time spent on selling agricultural produce, moderate use of forest products (poles), mostly use firewood for cooking; majority of which is obtained from natural forests, high proportion of temporary housing structures, land owned mostly under customary tenure

3 Moderate amount of time spent on crop cultivation activities, moderate amount of on-farm income, relatively high crop yields, lowest amount of time spent on livestock grazing, low number of livestock (lowest involvement in livestock husbandry), least involved in grocery shopping, low on-farm expenditure, lowest education level, low amount of time spent on food preparation, low time allocation to selling agricultural produce, low off-farm incomes, relatively high duration of gathering firewood, small farm sizes, moderate number of agricultural implements, moderate household size, low involvement in extension activities, relatively high number of household labour involved in cropping activities, low involvement in pest control activities, relatively high amount of time spent on food preparation and fetching water, moderate use of forest products (particularly timber), mixed proportions of housing unit types and land ownership regimes, mixed proportions of housing unit types and land ownership regimes, mostly use firewood as the main energy source for cooking, gathered from multiple sources

4 Lowest cultivation time and labour input, lowest yield and on-farm income, lowest household size, lowest education level for children, lowest number of agricultural implements, least farmland size, consumes the largest amount of firewood but spends relatively low amounts of time of firewood gathering, lowest amount of time spent on selling agricultural produce, lowest incomes from livestock, no evidence of use of forest products (poles and timber), moderate off-farm income, mixed proportions of housing unit types, land ownership regimes are mixed but notably has the highest proportion of leasehold land tenure type, mixed use of firewood and charcoal as main energy source for cooking obtained, firewood is mostly obtained from bush-lands

5 Relatively high amount of cultivation time and labour input, relatively high amount of on-farm income, Moderate income, pest relatively high crop yields, relatively high involvement in livestock husbandry, highest on-farm expenditure, controlling diversifying 
most involved in pest control, largest number of low input agricultural implements, spends time trading ownshop, highest amount of time spent on selling agricultural produce, relatively large household sizes, relatively high education levels, moderate farmland sizes, involved in agricultural extension activities, relatively high labour and time input to gathering firewood, high use of forest products (poles and timber), relatively high off-farm income, mixed proportions of housing unit types and land ownership regimes, mostly use firewood as the main energy source for cooking, gathered from multiple sources

$6 \quad$ Moderate agricultural time and labour input, highest amount of time spent on trading own-shop, relatively low onfarm incomes, relatively low crop yields, moderate amount of time spent on grazing livestock, moderate number of livestock, high livestock incomes, no forest product use recorded (poles and timber), moderately large household sizes, moderately involved in extension activities, low involvement in grocery shopping, moderate on-farm expenditure, limited involvement in pest control, moderate education levels, moderate farm size and agricultural implements, moderate amount of time gathering firewood and labour for fetching water and food preparation, moderate off-farm income, housing units are mostly permanent, mixed proportions of land ownership regimes, mixed use of firewood and charcoal as the main energy source for cooking; firewood is gathered from multiple sources

$7 \quad$ High involvement in agricultural production activities, highest off-farm income, moderate on-farm income, low yields, high involvement in livestock husbandry, most involved in agricultural extension activities, high time spent on grocery shopping and food preparation, moderate labour allocation to food preparation and fetching water, relatively high use of forest products (poles and timber), relatively high household sizes, moderate on-farm expenditure, no pest control activities, moderate education levels, highest total number of agricultural implements, high amount of time spent on and volume of firewood gathering, moderate amount of time selling agricultural produce and livestock income, moderate forest product use (poles and timber), moderate off-farm income, mixed proportions of housing unit types and land ownership regimes, mostly use firewood as the main energy source for cooking, gathered from multiple sources

8 Highest cultivation time and labour input, highest yields and on-farm income, largest household size (both nuclear and extended), highest education level for children, highest labour input for food preparation and fetching water, highest amount of time spent on gathering firewood, highest amount of time spent of food preparation, low forest product use, moderately involved in extension activities, moderate farm sizes, moderate onfarm expenditure, not involved in pest control activities, moderate number of agricultural implements, moderate livestock incomes, moderate off-farm income, mixed proportions of housing unit types, land ownership mostly under the customary systems, mostly use firewood as the main energy source for cooking, gathered from multiple sources

9 Highest cultivation time and labour input, highest yields and on-farm income, largest household size (both nuclear and extended), highest education level for children, highest labour input for food preparation and fetching water, highest amount of time spent on gathering firewood, highest amount of time spent of food preparation, low forest product use, moderately involved in extension activities, moderate farm sizes, moderate onfarm expenditure, not involved in pest control activities, high number of agricultural implements, moderate livestock incomes, moderate off-farm income, mixed proportions of housing unit types, land ownership mostly under the customary systems, mostly use firewood as the main energy source for cooking, gathered from multiple sources

${ }^{*}$ Cluster classification names are derived from outstanding characteristics from the continuous variables households with mixed crop and livestock farming

Moderate income, mixed

farming, shop-trading

households

Richest, "elite" mixed farming

and trading-based households

Moderate income, mixed farming agricultural extension activity oriented households

Large size, high labour and time inputting, moderate income, mixed farming households 
Supplement 1 Questionnaire continuous variables - category, definition and computation

Variable category

Hrs_weeding_dry season

Hrs_harvesting_wet season

Hrs_harvesting_dry season

season

Hrs_opening_agric.land dry

season

Hrs_postharvest_handling

wet season

Hrs_postharvest_handling

dry season

On-farm income

predominantly from

cropping activities

season
Cultivation time input

Hrs_opening_agric.land wet

Definition

Number of hours spent on weeding in the wet season of 2013

Number of hours spent on weeding in the dry season of 2013

Number of hours spent on harvesting in the wet season of 2013

Number of hours spent on harvesting in the dry season of 2013

Number of hours spent on opening agricultural land in the wet season of 2013

Number of hours spent on opening agricultural land in the dry season of 2013

Number of hours spent on postharvest handling in the wet season of 2013

Number of hours spent on postharvest handling in the dry season of 2013

Total income obtained from crops in the second half of 2013 (in UGX)

Tot_income_crop previous $\quad$ Total income obtained from crops in the first half of 2013 (in UGX)

season

Demographic

Mean_age_BC

Agricultural Extension activities
Tot_on-farm_income 2013

Tot_on-farm_income 2012

Tot yield current season

Tot_yield previous season

Hrs_grazing wet season

Hrs_grazing dry season

HHL_grazing dry season

HHL_grazing wet season

Tot_No_livestock 2013

Tot_No_livestock 2012

No_BC_HH

No_BC_boys

No_BC_girls

Tot_HH_size

Mean Educ BC

Total on-farm income obtained from both crop and livestock sales in 2013 (in UGX) Total on-farm income obtained from both crop and livestock sales in 2012 (in UGX) Total yield of all crops grown in the second half of 2013 (in kg)

Total yield of all crops grown in the first half of 2013 (in kg)

Number of hours spent on grazing in the wet season of 2013

Number of hours spent on grazing in the dry season of 2013

Number of household members who provide labour for grazing in the dry season Number of household members who provide labour for grazing in the wet season

Number of livestock (cattle, goats, sheep, and pigs) owned by the HH in 2013 Number of livestock (cattle, goats, sheep, and pigs) owned by the HH in 2012 Number of biological children in the household Number of male biological children in the household

Number of female biological children in the household

Total number of members in the household including all relative

Mean age of biological children in the household

Mean level of education of biological children (e.g. grade 1=1, grade 6=level 6, etc)

Hrs_extension meetings dry

Number of hours spent on attending extension meetings in the dry season of 2013

season

Hrs_extension_meetings wet Number of hours spent on attending extension meetings in the wet season of 2013

season

HHL_extension_meetings wet Number of household members who attend extension meetings in the wet season season

HHL_extension_meetings dry $\quad$ Number of household members who attend extension meetings in the dry season
Computation

Number of hours spent weeding in a day $\times$ number of weeding days in a wet season*

Number of hours spent weeding in a day $\times$ number of weeding days in a dry season**

Number of hours spent harvesting in a day $\times$ number of harvesting days in a wet season

Number of hours spent harvesting in a day $\times$ number of harvesting days in a dry season

Number of hours spent opening agric. land in a day $\times$ number of days spent opening agric. land in a wet season

Number of hours spent opening agric. land in a day $\times$ number of days spent opening agric. land in a dry season

Number of hours spent postharvest handling in a day $\times$ number of days spent on postharvest handling in a wet season

Number of hours spent postharvest handling in a day $\times$ number of days spent on postharvest handling in a dry season

Sum of all crop income from second half of 2013 crop sales

Sum of all crop income from first half of 2013 crop sales

Sum of on-farm income obtained from crop and livestock sales in 2013 Sum of on-farm income obtained from crop and livestock sales in 2012

Sum of yields of all crops grown in the second half of 2013

Sum of yields of all crops grown in the first half of 2013

Number of hours spent grazing in a day $\times$ number of days spent on grazing in a wet season

Number of hours spent grazing in a day $x$ number of days spent on grazing in a dry season

Tally of HH members providing labour for grazing in the dry season

Tally of HH members providing labour for grazing in the wet season

Tally of livestock numbers in 2013

Tally of livestock numbers in 2012

Tally of biological children in the househol

Tally of male biological children in the household

Tally of female biological children in the household

Tally of number of individuals in a household

Average of the ages of the biological children

Average level of education of biological children

Number of hours spent on attending extension meetings in a day $x$ number of extension meeting days in a dry season

Number of hours spent on attending extension meetings in a day $x$ number of extension meeting days in a wet season

Tally of HH members attending extension meetings in the wet season

Tally of HH members attending extension meetings in the dry season 
Cultivation labour

input
HHL_opening_agric.land wet

season

HHL_opening_agric.land dry

season

HHL_weeding wet season

HHL_weeding dry season

HHL_postharvest_handling

wet season

HHL_postharvest_handling

dry season

Household groceries Hrs_grocery_shopping wet

shopping

season

Hrs_grocery_shopping dry

season

HHL_grocery_shopping dry

season

HHL_grocery_shopping wet

season

On-farm expenditure Tot_expenditure_crop

previous season

Tot_expenditure_crop

current season

Tot_on-farm_expenditur

2012

Tot_on-farm_expenditure

2013

Pest-control activities $\quad$ HHL_pest_control dry season

HHL_pest_control wet season

Hrs_pest_control dry season

Hrs_pest_control wet season

No_other_relatives_HH

No_other_relatives_male

No_other_relatives_female

Education level

Educ_respondent

Educ_father

Educ_mother

Respondent's age

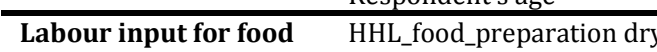

preparation and

season

HHL_food_preparation wet

season

fetching water
Number of household members who provide labour for opening agric. land in the wet season

Number of household members who provide labour for opening agric. land in the dry season

Number of household members who provide labour for weeding in the wet season

Number of household members who provide labour for weeding in the dry season

Number of household members who provide labour for postharvest handling in the wet season

Number of household members who provide labour for postharvest handling in the dry season

Number of hours spent on grocery shopping in the wet season of 2013

Number of hours spent on grocery shopping in the dry season of 2013

Number of household members who provide labour for grocery shopping in the dry season

Number of household members who provide labour for grocery shopping in the wet season

Total expenditure on crop production in the first half of 2013 on labour for opening land and weeding, buying seeds, fertiliser, pest control, buying/hiring cropping land Total expenditure on crop production in the $2^{\text {nd }}$ half of 2013 on labour for opening land and weeding, buying seeds, fertiliser, pest control, buying/hiring cropping land Total on-farm expenditure in 2012 including all cropping and livestock activities

Total on-farm expenditure in 2013 including all cropping and livestock activities season

Number of household members who provide labour for pest control in the wet season

Number of hours spent on pest control in the dry season of 2013

Number of hours spent on pest control in the wet season of 2013

Number of relatives other than those that comprise a nuclear family in a household:

these include grandparents, cousins, nieces, uncles, aunts, etc

Number of male relatives other than those that comprise a nuclear family in a household

Number of female relatives other than those that comprise a nuclear family in a household

Level of education of the respondent (e.g. grade 1=1, grade 6=level 6, etc)

Level of education of the father in the household

Level of education of the mother in the household

Age of respondent in years

for of household members who provide labour for food preparation in the dry season season
Tally of HH members providing labour for opening agric. land in the wet season

of $\mathrm{HH}$ members providing labour for opening agric. land in the dry

Tally of HH members providing labour for weeding in the wet season Tally of HH members providing labour for weeding in the dry season Tally of HH members providing labour for postharvest handling in the wet season

ally of HH members providing labour for postharvest handling in the dry

Number of hours spent on grocery shopping in a day $\times$ number of grocery shopping days in a wet season

Number of hours spent on grocery shopping in a day $\times$ number of grocery shopping days in a dry season

Tally of HH members providing labour for grocery shopping in the dry season

Tally of HH members providing labour for grocery shopping in the wet season

expenditure on labour for opening land and weeding buying seeds, fertiliser, pest control, buying/hiring cropping land

Sum of expenditure on labour for opening land and weeding buying seeds, fertiliser, pest control, buying/hiring cropping land

Sum of expenditure on cropping and livestock activities

Sum of expenditure on cropping and livestock activities

Tally of HH members providing labour for pest control in the dry season Tally of HH members providing labour for pest control in the wet season

Number of hours spent on pest control in a day $\times$ number of pest control days in a dry season

Number of hours spent on pest control in a day $\times$ number of pest control days in a wet season

Tally of relatives other than those that comprise a nuclear family in a household

Tally of male relatives other than those that comprise a nuclear family in a household

Tally of female relatives other than those that comprise a nuclear family in a household

Record of education level response

Record of education level response

Record of education level response

Record of age

Tally of HH members providing labour for food preparation in the dry season

The wet season 


\begin{tabular}{|c|c|c|c|}
\hline & $\begin{array}{l}\text { HHL_fetching_water dry } \\
\text { season }\end{array}$ & $\begin{array}{l}\text { Number of household members who provide labour for fetching water in the dry } \\
\text { season }\end{array}$ & Tally of HH members providing labour for fetching water in the dry season \\
\hline & $\begin{array}{l}\text { HHL_fetching_water wet } \\
\text { season }\end{array}$ & $\begin{array}{l}\text { Number of household members who provide labour for fetching water in the wet } \\
\text { season }\end{array}$ & $\begin{array}{l}\text { Tally of } \mathrm{HH} \text { members providing labour for fetching water in the wet } \\
\text { season }\end{array}$ \\
\hline \multirow{5}{*}{$\begin{array}{l}\text { Agricultural } \\
\text { implements and farm } \\
\text { size }\end{array}$} & Tot_No_farm_implements & Total number of farm implements used including low and high input tools & Sum of low and high input implements used on the farm \\
\hline & Tot_No_low_input tools & $\begin{array}{l}\text { Low cost tools used on the farm (including: hand hoe, forked hoe, panga, slasher, } \\
\text { sickle, spade, axe, wheel barrow) }\end{array}$ & Tally of low input tools \\
\hline & Tot_No_high_input tools & $\begin{array}{l}\text { High cost agricultural implements (including. tractor, animal plough, disc harrow, } \\
\text { planter, spray pump, milk machines, feed troughs) }\end{array}$ & Tally of high input tools \\
\hline & $\begin{array}{l}\text { Tot_farmland_size previous } \\
\text { season }\end{array}$ & $\begin{array}{l}\text { Total size of land under both annual and perennial crops in the } 1 \text { st half of } 2013 \text { (in } \\
\text { ha), owned by a household in perpetuity except where it was clarified that land was } \\
\text { rented (especially in semi-arid AEZ of Buliisa) }\end{array}$ & Sum of area of land under each crop enterprise in the $1^{\text {st }}$ half of $2013^{* * *}$ \\
\hline & $\begin{array}{l}\text { Tot_farmland_size current } \\
\text { season }\end{array}$ & $\begin{array}{l}\text { Total size of land under both annual and perennial crops in the } 2^{\text {nd }} \text { half of } 2013 \text { (in } \\
\text { ha), owned by a household in perpetuity except where it was clarified that land was } \\
\text { rented (especially in semi-arid AEZ of Buliisa) }\end{array}$ & Sum of area of land under each crop enterprise in the $2^{\text {nd }}$ half of 2013 \\
\hline \multirow[t]{3}{*}{ Firewood gathering } & $\begin{array}{l}\text { Hrs_gathering_firewood wet } \\
\text { season }\end{array}$ & Number of hours spent on firewood gathering in the wet season of 2013 & $\begin{array}{l}\text { Number of hours spent on firewood gathering in a day } \times \text { number of } \\
\text { firewood gathering days in a wet season }\end{array}$ \\
\hline & $\begin{array}{l}\text { Hrs_gathering_firewood dry } \\
\text { season }\end{array}$ & Number of hours spent on firewood gathering in the dry season of 2013 & $\begin{array}{l}\text { Number of hours spent on firewood gathering in a day } \times \text { number of } \\
\text { firewood gathering days in a dry season }\end{array}$ \\
\hline & 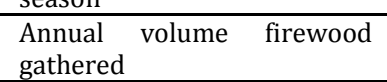 & Total volume of firewood gathered in a year & $\begin{array}{l}\prod \mathrm{r}^{2} \mathrm{~h} \times \text { number of logs in a bundle } \times \text { number of days firewood is gathered } \\
\text { in a year (estimates computed from weekly collection) }\end{array}$ \\
\hline \multirow[t]{2}{*}{$\begin{array}{l}\text { Fetching water time } \\
\text { budget }\end{array}$} & $\begin{array}{l}\text { Hrs_fetching_water wet } \\
\text { season }\end{array}$ & Number of hours spent on fetching water in the wet season of 2013 & $\begin{array}{l}\text { Number of hours spent on fetching water in a day } \times \text { number of fetching } \\
\text { water days in a wet season }\end{array}$ \\
\hline & $\begin{array}{l}\text { Hrs_fetching_water dry } \\
\text { season }\end{array}$ & Number of hours spent on fetching water in the dry season of 2013 & $\begin{array}{l}\text { Number of hours spent on fetching water in a day } \times \text { number of fetching } \\
\text { water days in a dry season }\end{array}$ \\
\hline \multirow[t]{2}{*}{$\begin{array}{l}\text { Trading own-shop } \\
\text { time budget }\end{array}$} & $\begin{array}{l}\text { Hrs_trading_own_shop dry } \\
\text { season }\end{array}$ & $\begin{array}{l}\text { Number of hours spent on selling merchandise in a household-owned shop in the } \\
\text { dry season of } 2013\end{array}$ & $\begin{array}{l}\text { Number of hours spent on trading own-shop in a day } \times \text { number of trading } \\
\text { own-shop days in a dry season }\end{array}$ \\
\hline & $\begin{array}{l}\text { Hrs_trading_own_shop wet } \\
\text { season }\end{array}$ & $\begin{array}{l}\text { Number of hours spent on selling merchandise in a household-owned shop in the } \\
\text { wet season of } 2013\end{array}$ & $\begin{array}{l}\text { Number of hours spent on trading own-shop in a day } \times \text { number of trading } \\
\text { own-shop days in a wet season }\end{array}$ \\
\hline \multirow[t]{2}{*}{$\begin{array}{l}\text { Food preparation time } \\
\text { budget }\end{array}$} & $\begin{array}{l}\text { Hrs_food_preparation dry } \\
\text { season }\end{array}$ & Number of hours spent on food preparation in the dry season of 2013 & $\begin{array}{l}\text { Number of hours spent on food preparation in a day } \times \text { number of food } \\
\text { preparation days in a dry season }\end{array}$ \\
\hline & $\begin{array}{l}\text { Hrs_food_preparation wet } \\
\text { season }\end{array}$ & Number of hours spent on food preparation in the wet season of 2013 & $\begin{array}{l}\text { Number of hours spent on food preparation in a day } \times \text { number of food } \\
\text { preparation days in a wet season }\end{array}$ \\
\hline \multirow[t]{2}{*}{$\begin{array}{l}\text { Selling agricultural } \\
\text { produce time budget }\end{array}$} & $\begin{array}{l}\text { Hrs_selling_agric.produce dry } \\
\text { season }\end{array}$ & Number of hours spent on selling agricultural produce in the dry season of 2013 & $\begin{array}{l}\text { Number of hours spent on selling agric. produce in a day } \times \text { number of } \\
\text { selling agric. produce days in a dry season }\end{array}$ \\
\hline & $\begin{array}{l}\text { Hrs_selling_agric.produce } \\
\text { wet season }\end{array}$ & Number of hours spent on selling agricultural produce in the wet season of 2013 & $\begin{array}{l}\text { Number of hours spent on selling agric. produce in a day } \times \text { number of } \\
\text { selling agric. produce days in a wet season }\end{array}$ \\
\hline \multirow[t]{2}{*}{ Marriage age } & Clan_marriage_age_girls & Age at which girls in the clan get married & Record of response \\
\hline & $\begin{array}{l}\text { Clan_marriage_age_boys } \\
\end{array}$ & Age at which boys in the clan get married & Record of response \\
\hline \multirow{2}{*}{ Livestock income } & Tot_income_livestock 2013 & Total income from selling livestock and livestock products in 2013 & Lump-sum estimate of livestock income in 2013 (record of response) \\
\hline & Tot_income_livestock 2012 & Total income from selling livestock and livestock products in 2012 & Lump-sum estimate of livestock income in 2012 (record of response) \\
\hline \multirow[t]{2}{*}{ Forest products used } & Quantity of poles & Volume of poles gathered from a natural forest in 2013 & $\prod \mathrm{r}^{2} \mathrm{~h} \times$ number of poles gathered in a year \\
\hline & Quantity of timber & Volume of timber extracted from a natural forest in 2013 & $\mathrm{~L} \times \mathrm{W} \times \mathrm{h} \times$ number of timber pieces extracted in a year \\
\hline \multirow[t]{2}{*}{ HH off-farm income } & HH_off-farm_income_BC & Total amount of off-farm income earned by biological children in the HH (in UGX) & Sum of off-farm income earned by each biological child in the $\mathrm{HH}$ \\
\hline & HH_tot_off-farm_income & Total amount of off-farm income earned by all members of the HH combined (UGX) & Sum of off-farm income of all members of the $\mathrm{HH}$ \\
\hline
\end{tabular}




\section{Supplement 2 Descriptive statistics of the continuous variables used in the analysis $(n=706)$}

\begin{tabular}{|c|c|c|c|c|c|c|c|c|}
\hline Variable & & & & Rav & data & & & \\
\hline Household demographic data & Mean & $\begin{array}{l}\text { Lower } \\
\text { B }\end{array}$ & Upper B & Median & St.dev & Min & Max & Skewness \\
\hline Respondent's age & 38.95 & 37.74 & 40.17 & 35.50 & 16.46 & 15.00 & 93.00 & 0.83 \\
\hline Total household size & 6.34 & 6.11 & 6.56 & 6.00 & 3.03 & 1.00 & 22.00 & 0.91 \\
\hline No. biological children & 3.57 & 3.39 & 3.74 & 3.00 & 2.36 & 0.00 & 10.00 & 0.50 \\
\hline Mean age biological $\mathrm{Ch}$. & 13.32 & 12.48 & 14.17 & 11.00 & 11.39 & 0.00 & 63.00 & 1.14 \\
\hline Respondent's educ. level & 5.85 & 5.54 & 6.17 & 6.00 & 4.24 & 0.00 & 16.00 & 0.28 \\
\hline Father's educ. level & 5.66 & 5.31 & 6.01 & 6.00 & 4.77 & 0.00 & 17.00 & 0.29 \\
\hline Mother's educ. level & 4.50 & 4.19 & 4.80 & 5.00 & 4.11 & 0.00 & 16.00 & 0.52 \\
\hline Off-farm inc. biological children ( $\times 10^{5}$ UGX) & 1.04 & 0.52 & 1.56 & 0.00 & 7.02 & 0.00 & 108.00 & 9.50 \\
\hline Tot. HH. Off-farm inc. (x105 UGX) & 15.47 & 13.39 & 17.56 & 0.00 & 28.25 & 0.00 & 225.60 & 3.02 \\
\hline Clan marriage age for girls & 18.30 & 18.16 & 18.45 & 18.00 & 2.00 & 12.00 & 30.00 & 0.68 \\
\hline Clan marriage age for boys & 20.48 & 20.24 & 20.71 & 20.00 & 3.22 & 14.00 & 57.00 & 3.34 \\
\hline Land use/cropping & Mean & $\begin{array}{l}\text { Lower } \\
\text { B }\end{array}$ & Upper B & Median & St.dev & Min & Max & Skewness \\
\hline Tot_No_low_input tools & 7.20 & 6.75 & 7.65 & 6.00 & 6.10 & 0.00 & 75.00 & 4.55 \\
\hline Tot_No_high_input tools & 0.39 & 0.30 & 0.48 & 0.00 & 1.27 & 0.00 & 18.00 & 7.87 \\
\hline Tot_No_farm_implements & 7.79 & 7.09 & 8.09 & 6.00 & 6.77 & 0.00 & 87.00 & 4.67 \\
\hline Tot_farmland_size previous season (ha) & 0.64 & 0.57 & 0.70 & 0.41 & 0.89 & 0.00 & 10.19 & 4.00 \\
\hline Tot_farmland_size current season (ha) & 0.63 & 0.57 & 0.70 & 0.41 & 0.89 & 0.00 & 9.38 & 3.47 \\
\hline Tot_yield previous season (kg) & 4060.3 & 2089.3 & 6031.3 & 150.00 & 26674.4 & 0.00 & 351550 & 9.85 \\
\hline Tot_yield current season (kg) & 3638.5 & 1778.6 & 5498.3 & 60.00 & 25170.3 & 0.00 & 351550 & 10.71 \\
\hline Tot_income_crop previous season (x105 UGX) & 4.40 & 3.03 & 5.77 & 0.00 & 18.53 & 0.00 & 214.40 & 8.10 \\
\hline Tot_income_crop current season (x $10^{5}$ UGX) & 3.97 & 2.56 & 537 & 0.00 & 19.06 & 0.00 & 245.15 & 8.85 \\
\hline $\begin{array}{l}\text { Tot_expenditure_crop previous season }\left(\mathrm{x} 10^{5}\right. \\
\text { UGX) }\end{array}$ & 0.86 & 0.66 & 1.06 & 0.00 & 2.69 & 0.00 & 38.00 & 7.28 \\
\hline $\begin{array}{l}\text { Tot_expenditure_crop current season }\left(\mathrm{x} 10^{5}\right. \\
\text { UGX) }\end{array}$ & 0.84 & 0.62 & 1.06 & 0.00 & 2.97 & 0.00 & 38.00 & 8.16 \\
\hline Livestock inventory & Mean & $\begin{array}{l}\text { Lower } \\
\text { B }\end{array}$ & Upper B & Median & St.dev & Min & Max & Skewness \\
\hline Tot. No. large ruminants 2012 & 1.02 & 0.67 & 1.38 & 0.00 & 4.81 & 0.00 & 50.00 & 6.96 \\
\hline Tot. No. large ruminants 2013 & 0.93 & 0.61 & 1.25 & 0.00 & 4.33 & 0.00 & 50.00 & 7.22 \\
\hline Tot. No. small ruminants 2012 & 2.46 & 2.06 & 2.86 & 0.00 & 5.42 & 0.00 & 76.00 & 5.89 \\
\hline Tot. No. small ruminants 2013 & 2.32 & 2.03 & 2.61 & 0.00 & 3.98 & 0.00 & 30.00 & 3.35 \\
\hline Tot. Income livestock 2012 (x105 UGX) & 0.71 & 0.39 & 1.03 & 0.00 & 4.34 & 0.00 & 80.00 & 11.90 \\
\hline Tot. Income livestock $2013\left(\mathrm{x} 10^{5} \mathrm{UGX}\right)$ & 0.12 & 0.00 & 0.24 & 0.00 & 1.59 & 0.00 & 38.00 & 20.63 \\
\hline Tot. On-farm income 2012 (x10 UGX) & 5.11 & 3.69 & 6.52 & 0.00 & 19.13 & 0.00 & 214.14 & 7.53 \\
\hline Tot On-farm income 2013 (x105 UGX) & 4.09 & 2.67 & 5.50 & 0.00 & 19.11 & 0.00 & 245.15 & 8.77 \\
\hline Tot On-farm Expenditure 2012 (x105 UGX) & 0.88 & 0.70 & 1.06 & 0.00 & 2.48 & 0.00 & 35.00 & 6.47 \\
\hline Tot On-farm Expenditure 2013 (x105 UGX) & 0.92 & 0.69 & 1.16 & 0.00 & 3.15 & 0.00 & 46.12 & 8.32 \\
\hline Energy and forest product use & Mean & $\begin{array}{l}\text { Lower } \\
\text { B }\end{array}$ & Upper B & Median & St.dev & Min & Max & Skewness \\
\hline Volume firewood used per annum $\left(\mathrm{m}^{3}\right)$ & 35.84 & 29.17 & 42.50 & 16.52 & 90.14 & & 143.39 & 10.54 \\
\hline Volume of timber obtained per annum $\left(\mathrm{m}^{3}\right)$ & 1.14 & 0.42 & 1.85 & 0.00 & 9.65 & 0.00 & 135.92 & 10.77 \\
\hline Volume of poles obtained per annum $\left(\mathrm{m}^{3}\right)$ & 1.10 & 0.44 & 1.76 & 0.00 & 8.89 & 0.00 & 141.43 & 10.85 \\
\hline Household time budgets in 2013 & Mean & $\begin{array}{l}\text { Lower } \\
\text { B }\end{array}$ & Upper B & Median & St.dev & Min & Max & Skewness \\
\hline Hrs_opening_agric.land dry season & 51.96 & 47.05 & 56.88 & 28.00 & 66.50 & 0.00 & 480.00 & 2.42 \\
\hline Hrs_opening_agric.land wet season & 51.42 & 46.49 & 56.35 & 28.00 & 66.73 & 0.00 & 480.00 & 2.48 \\
\hline Hrs_fetching_water dry season & 154.41 & 143.98 & 164.84 & 121.33 & 141.13 & 0.00 & 1274.00 & 2.90 \\
\hline Hrs_fetching_water wet season & 147.27 & 138.06 & 156.48 & 91.50 & 124.62 & 0.00 & 1098.00 & 2.46 \\
\hline Hrs_gathering_firewood dry season & 176.63 & 160.44 & 192.82 & 104.00 & 218.47 & 0.00 & 1274.00 & 2.12 \\
\hline Hrs_gathering_firewood wet season & 181.04 & 164.08 & 198.00 & 104.56 & 228.90 & 0.00 & 1829.80 & 2.39 \\
\hline Hrs grazing dry season & 186.24 & 148.05 & 224.42 & 0.00 & 516.38 & 0.00 & 2184.00 & 2.97 \\
\hline Hrs grazing wet season & 187.15 & 148.69 & 225.61 & 0.00 & 520.15 & 0.00 & 2196.00 & 3.00 \\
\hline Hrs_extension_meetings dry season & 1.96 & 1.64 & 2.29 & 0.00 & 4.44 & 0.00 & 25.00 & 2.86 \\
\hline Hrs_extension_meetings wet season & 1.95 & 1.62 & 2.27 & 0.00 & 4.41 & 0.00 & 25.00 & 2.88 \\
\hline Hrs_food_preparation dry season & 586.25 & 562.41 & 610.08 & 546.00 & 322.57 & 0.00 & 2184.00 & 1.01 \\
\hline Hrs_food_preparation wet season & 598.71 & 574.03 & 623.39 & 549.00 & 333.99 & 0.00 & 2196.00 & 1.05 \\
\hline Hrs_weeding_dry season & 47.99 & 43.66 & 52.32 & 24.00 & 58.44 & 0.00 & 360.00 & 1.86 \\
\hline Hrs_weeding_wet season & 51.16 & 46.66 & 55.65 & 28.00 & 60.64 & 0.00 & 360.00 & 1.93 \\
\hline Hrs_harvesting_dry season & 21.01 & 19.51 & 22.51 & 18.00 & 20.23 & 0.00 & 168.00 & 2.09 \\
\hline Hrs_harvesting_wet season & 21.25 & 19.67 & 22.83 & 18.00 & 21.34 & 0.00 & 210.00 & 2.44 \\
\hline Hrs_pest_control dry season & 0.68 & 0.41 & 0.95 & 0.00 & 3.64 & 0.00 & 42.00 & 7.57 \\
\hline
\end{tabular}




\begin{tabular}{|c|c|c|c|c|c|c|c|c|}
\hline Hrs_pest_control wet season & 0.76 & 0.47 & 1.05 & 0.00 & 3.87 & 0.00 & 42.00 & 7.13 \\
\hline Hrs_opening_agric.land dry season & 18.71 & 17.16 & 20.25 & 15.00 & 20.85 & 0.00 & 160.00 & 2.29 \\
\hline Hrs_postharvest_handling wet season & 23.98 & 21.79 & 26.16 & 16.00 & 29.49 & 0.00 & 240.00 & 2.30 \\
\hline Hrs_selling_agric.produce dry season & 3.75 & 2.86 & 4.64 & 0.00 & 12.00 & 0.00 & 140.00 & 6.32 \\
\hline Hrs_selling_agric.produce wet season & 4.06 & 2.94 & 5.18 & 0.00 & 15.11 & 0.00 & 240.00 & 9.47 \\
\hline Hrs_trading_own_shop dry season & 113.36 & 79.34 & 147.37 & 0.00 & 459.04 & 0.00 & 2912.00 & 3.99 \\
\hline Hrs_trading_own_shop wet season & 113.30 & 79.25 & 147.35 & 0.00 & 459.51 & 0.00 & 2928.00 & 4.01 \\
\hline Hrs off-farm jobs dry season & 346.39 & 301.54 & 391.25 & 0.00 & 575.14 & 0.00 & 3120.00 & 1.45 \\
\hline Household labour budgets in 2013 & Mean & $\begin{array}{l}\text { Lower } \\
\text { B }\end{array}$ & Upper B & Median & St.dev & Min & Max & Skewness \\
\hline HHL_opening_agric.land wet season & 1.88 & 1.76 & 1.99 & 2.00 & 1.57 & 0.00 & 14.00 & 1.76 \\
\hline HHL_opening_agric.land dry season & 1.87 & 1.75 & 1.98 & 2.00 & 2.00 & 0.00 & 14.00 & 1.77 \\
\hline HHL_fetching_water dry season & 1.68 & 1.58 & 1.77 & 1.00 & 1.33 & 0.00 & 8.00 & 2.04 \\
\hline HHL_fetching_water wet season & 1.22 & 1.14 & 1.30 & 1.00 & 1.07 & 0.00 & 7.00 & 1.87 \\
\hline HHL_grazing wet season & 0.26 & 0.22 & 0.30 & 0.00 & 0.57 & 0.00 & 6.00 & 3.29 \\
\hline HHL_extension_meetings wet season & 0.32 & 0.27 & 0.37 & 0.00 & 0.68 & 0.00 & 5.00 & 3.04 \\
\hline HHL_extension_meetings dry season & 0.33 & 0.28 & 0.38 & 0.00 & 0.69 & 0.00 & 5.00 & 3.07 \\
\hline HHL_food_preparation wet season & 1.23 & 1.17 & 1.28 & 1.00 & 0.71 & 0.00 & 6.00 & 3.19 \\
\hline HHL_food_preparation dry season & 1.23 & 1.17 & 1.28 & 1.00 & 0.71 & 0.00 & 6.00 & 3.21 \\
\hline HHL_weeding wet season & 1.78 & 1.67 & 1.90 & 2.00 & 1.59 & 0.00 & 14.00 & 1.82 \\
\hline HHL_weeding dry season & 1.74 & 1.62 & 1.86 & 2.00 & 1.63 & 0.00 & 14.00 & 1.79 \\
\hline HHL_pest_control wet season & 0.13 & 0.08 & 0.17 & 0.00 & 0.59 & 0.00 & 6.00 & 6.60 \\
\hline HHL_pest_control dry season & 0.11 & 0.08 & 0.15 & 0.00 & 0.53 & 0.00 & 6.00 & 6.83 \\
\hline HHL_postharvest_handling wet season & 1.29 & 1.20 & 1.37 & 1.00 & 1.20 & 0.00 & 6.00 & 1.53 \\
\hline HHL_postharvest_handling dry season & 1.28 & 1.19 & 1.37 & 1.00 & 1.18 & 0.00 & 6.00 & 1.56 \\
\hline HHL_grocery_shopping wet season & 0.88 & 0.81 & 0.94 & 1.00 & 0.88 & 0.00 & 8.00 & 2.67 \\
\hline HHL_postharvest_handling dry season & 0.88 & 0.81 & 0.94 & 1.00 & 0.88 & 0.00 & 8.00 & 2.66 \\
\hline
\end{tabular}


Supplement 4 Total variance explained (rotated solution)

\begin{tabular}{|c|c|c|c|c|c|c|}
\hline \multirow[t]{2}{*}{ Component } & \multicolumn{3}{|c|}{ Initial Eigen Value } & \multicolumn{3}{|c|}{ Rotation sum of squares loadings } \\
\hline & Total & $\begin{array}{l}\% \text { of } \\
\text { Variance }\end{array}$ & $\begin{array}{l}\text { Cumulative } \\
\%\end{array}$ & Total & $\begin{array}{l}\% \\
\text { Variance }\end{array}$ & $\begin{array}{l}\text { Cumulative } \\
\%\end{array}$ \\
\hline 1 & 17.9 & 21.6 & 21.6 & 8.4 & 10.1 & 10.1 \\
\hline 2 & 7.1 & 8.6 & 30.2 & 4.9 & 5.9 & 16.0 \\
\hline 3 & 4.8 & 5.7 & 35.9 & 4.8 & 5.8 & 21.8 \\
\hline 4 & 4.0 & 4.9 & 40.8 & 4.2 & 5.0 & 26.8 \\
\hline 5 & 3.7 & 4.4 & 45.2 & 4.1 & 4.9 & 31.7 \\
\hline 6 & 3.1 & 3.7 & 48.9 & 4.0 & 4.9 & 36.6 \\
\hline 7 & 2.9 & 3.5 & 52.4 & 3.7 & 4.5 & 41.1 \\
\hline 8 & 2.7 & 3.3 & 55.7 & 3.7 & 4.4 & 45.5 \\
\hline 9 & 2.5 & 3.0 & 58.7 & 3.6 & 4.3 & 49.8 \\
\hline 10 & 2.2 & 2.7 & 61.4 & 3.1 & 3.7 & 53.5 \\
\hline 11 & 2.1 & 2.5 & 63.9 & 2.7 & 3.3 & 56.8 \\
\hline 12 & 2.0 & 2.4 & 66.3 & 2.7 & 3.2 & 60.0 \\
\hline 13 & 1.7 & 2.1 & 68.4 & 2.4 & 2.9 & 62.9 \\
\hline 14 & 1.7 & 2.0 & 70.4 & 2.3 & 2.8 & 65.7 \\
\hline 15 & 1.5 & 1.8 & 72.2 & 2.1 & 2.6 & 68.3 \\
\hline 16 & 1.3 & 1.6 & 73.8 & 2.1 & 2.5 & 70.8 \\
\hline 17 & 1.3 & 1.6 & 75.4 & 2.0 & 2.5 & 73.3 \\
\hline 18 & 1.2 & 1.5 & 76.9 & 1.6 & 1.9 & 75.2 \\
\hline 19 & 1.2 & 1.4 & 78.3 & 1.6 & 1.9 & 77.1 \\
\hline 20 & 1.1 & 1.3 & 79.6 & 1.4 & 1.7 & 78.8 \\
\hline 21 & 1.0 & 1.25 & 80.9 & 1.4 & 1.7 & 80.5 \\
\hline 22 & 1.0 & 1.21 & 82.1 & 1.3 & 1.5 & 82.0 \\
\hline
\end{tabular}


Supplement 5 Rotated Component matrix - loadings of variables per component

Variable

Category Variable

Component

\begin{tabular}{|c|c|c|c|c|c|c|c|c|c|c|c|c|c|c|c|c|c|c|c|c|c|c|c|}
\hline & & 1 & 2 & 3 & 4 & 5 & 6 & 7 & 8 & 9 & 10 & 11 & 12 & 13 & 14 & 15 & 16 & 17 & 18 & 19 & 20 & 21 & 22 \\
\hline \multirow{8}{*}{$\begin{array}{l}\text { Cultivation } \\
\text { time input }\end{array}$} & Hrs_weeding_wet season & 0.86 & 0.13 & 0.10 & 0.07 & 0.12 & 0.16 & 0.14 & 0.08 & -0.07 & 0.11 & -0.01 & 0.02 & 0.02 & 0.12 & 0.04 & 0.00 & 0.10 & 0.03 & -0.00 & 0.00 & -0.03 & -0.002 \\
\hline & $\begin{array}{l}\text { Hrs_harvesting_wet } \\
\text { season }\end{array}$ & 0.84 & 0.16 & 0.05 & 0.06 & 0.02 & 0.17 & 0.09 & 0.08 & 0.03 & 0.01 & 0.04 & -0.00 & 0.10 & 0.07 & 0.08 & -0.02 & 0.09 & 0.04 & 0.02 & 0.04 & 0.03 & 0.04 \\
\hline & Hrs_harvesting_dry season & 0.84 & .15 & 0.06 & 0.05 & 0.03 & 0.17 & 0.09 & 0.09 & 0.02 & 0.01 & 0.03 & -0.01 & 0.11 & 0.08 & 0.08 & -0.04 & 0.09 & 0.02 & 0.01 & 0.02 & 0.06 & 0.01 \\
\hline & $\begin{array}{l}\text { Hrs_opening_agric.land } \\
\text { wet season }\end{array}$ & 0.84 & 0.15 & 0.06 & 0.07 & 0.03 & 0.15 & 0.13 & 0.10 & 0.01 & 0.10 & -0.07 & 0.04 & 0.03 & 0.13 & 0.04 & 0.03 & 0.10 & -0.01 & 0.02 & 0.01 & -0.00 & 0.09 \\
\hline & Hrs_weeding_dry season & 0.83 & 0.11 & 0.11 & 0.08 & -0.03 & 0.16 & 0.13 & 0.07 & 0.00 & 0.11 & -0.02 & 0.03 & -0.01 & 0.15 & 0.03 & -0.05 & 0.07 & 0.04 & 0.01 & 0.04 & -0.06 & -0.01 \\
\hline & $\begin{array}{l}\text { Hrs_opening_agric.land } \\
\text { dry season }\end{array}$ & 0.82 & 0.16 & 0.07 & 0.07 & 0.04 & 0.17 & 0.17 & 0.08 & 0.02 & 0.11 & -0.06 & 0.03 & 0.03 & 0.14 & 0.04 & 0.03 & 0.12 & -0.01 & 0.01 & 0.01 & 0.01 & 0.09 \\
\hline & $\begin{array}{l}\text { Hrs_postharvest_handling } \\
\text { wet season }\end{array}$ & 0.81 & 0.05 & -0.03 & 0.06 & 0.11 & 0.16 & 0.09 & 0.06 & 0.04 & -0.01 & -0.02 & 0.04 & 0.03 & 0.05 & 0.10 & -0.06 & -0.04 & 0.09 & 0.04 & 0.00 & -0.06 & -0.13 \\
\hline & $\begin{array}{l}\text { Hrs_postharvest_handling } \\
\text { dry season }\end{array}$ & 0.80 & .03 & 0.04 & 0.05 & 11 & 20 & 0.06 & 0.06 & 0.05 & -0.04 & -0.02 & 0.01 & 0.05 & 0.03 & 0.10 & -0.05 & -0.07 & 0.09 & 0.03 & -0.00 & -0.06 & -0.13 \\
\hline \multirow{6}{*}{$\begin{array}{l}\text { On-farm } \\
\text { income } \\
\text { predominantly } \\
\text { from cropping } \\
\text { activities }\end{array}$} & $\begin{array}{l}\text { Tot_income_crop current } \\
\text { season }\end{array}$ & 0.15 & 0.88 & 0.07 & 0.01 & 0.12 & 0.02 & -0.03 & 0.13 & 0.14 & 0.04 & 0.03 & 0.04 & 0.05 & 0.03 & -0.03 & -0.03 & -0.01 & 0.11 & 0.04 & 0.01 & -0.04 & -0.02 \\
\hline & Tot_on-farm_income 2013 & 0.16 & 0.86 & 0.08 & 0.03 & 0.11 & 0.01 & $\begin{array}{c}-0.04 \\
\end{array}$ & 0.14 & 0.13 & 0.03 & 0.03 & 0.04 & 0.06 & 0.01 & -0.03 & -0.02 & -0.02 & 0.11 & 0.03 & 0.15 & -0.03 & -0.03 \\
\hline & $\begin{array}{l}\text { Tot_income_crop previous } \\
\text { season }\end{array}$ & 0.16 & 0.81 & 0.01 & -0.03 & 0.12 & 0.11 & -0.02 & 0.18 & 0.07 & -0.02 & 0.07 & -0.04 & 0.10 & 0.08 & -0.03 & 0.02 & 0.03 & 0.17 & 0.02 & 0.09 & 0.06 & 0.07 \\
\hline & Tot_on-farm_income 2012 & 0.17 & 0.78 & 0.13 & 0.01 & 0.13 & 0.15 & 0.01 & 0.17 & 0.03 & $\begin{array}{l}0.03 \\
\end{array}$ & $\begin{array}{l}0.07 \\
\end{array}$ & -0.06 & 0.12 & 0.06 & -0.02 & 0.03 & 0.04 & $\begin{array}{l}0.10 \\
\end{array}$ & 0.02 & 0.20 & 0.07 & 0.09 \\
\hline & Tot_yield current season & 0.25 & 0.64 & 0.16 & 0.08 & 0.16 & 0.11 & -0.01 & 0.17 & 0.10 & 0.16 & 0.05 & 0.08 & 0.02 & -0.04 & -0.03 & -0.07 & 0.05 & -0.02 & -0.04 & -2.0 & 0.11 & -0.04 \\
\hline & Tot_yield previous season & 0.41 & 0.58 & 0.13 & 0.10 & 0.11 & 0.15 & -0.02 & 0.18 & 0.10 & 0.06 & 0.09 & 0.00 & 0.23 & 0.12 & -0.02 & -0.03 & 0.01 & 0.02 & -0.03 & -0.14 & 0.17 & 0.00 \\
\hline \multirow{6}{*}{$\begin{array}{l}\text { Livestock } \\
\text { husbandry }\end{array}$} & Hrs_grazing wet season & 0.07 & 0.06 & 0.89 & 0.05 & 0.09 & 0.00 & -0.05 & 0.13 & 0.05 & 0.11 & 0.02 & -0.01 & 0.06 & 0.03 & -0.03 & -0.02 & 0.01 & 0.06 & -0.01 & 0.13 & -0.02 & 0.01 \\
\hline & Hrs_grazing dry season & 0.06 & 0.06 & 0.89 & 0.05 & 0.09 & 0.00 & -0.05 & 0.13 & 0.05 & 0.11 & 0.02 & -0.01 & 0.06 & 0.03 & -0.01 & -0.03 & 0.01 & 0.06 & -0.01 & 0.13 & -0.02 & 0.00 \\
\hline & HHL_grazing dry season & 0.04 & 0.11 & 0.88 & 0.07 & 0.08 & 0.13 & 0.03 & 0.08 & 0.03 & 0.03 & -0.04 & 0.10 & 0.01 & -0.03 & 0.00 & -0.01 & 0.01 & 0.03 & -0.02 & -0.14 & 0.12 & 0.10 \\
\hline & HHL_grazing wet season & 0.05 & 0.12 & 0.87 & 0.06 & 0.09 & 0.13 & 0.03 & 0.08 & 0.03 & 0.04 & -0.04 & 0.01 & -0.02 & -0.03 & 0.01 & -0.01 & 0.01 & 0.04 & -0.01 & -0.14 & 0.12 & 0.10 \\
\hline & Tot_No_livestock 2013 & 0.15 & 0.01 & 0.66 & 0.13 & 0.10 & 0.01 & 0.12 & 0.11 & 0.07 & 0.02 & 0.00 & 0.08 & 0.18 & 0.22 & -0.02 & -0.03 & 0.03 & 0.00 & 0.09 & 0.41 & -0.12 & -0.07 \\
\hline & Tot_No_livestock 2012 & 0.15 & 0.04 & 0.66 & 0.13 & 0.15 & -0.02 & 0.08 & 0.10 & 0.00 & 0.04 & 0.03 & 0.08 & 0.21 & 0.19 & -0.04 & 0.01 & 0.03 & -0.01 & 0.05 & 0.43 & -0.09 & -0.01 \\
\hline \multirow{6}{*}{$\begin{array}{l}\text { Demographic } \\
\text { characteristics }\end{array}$} & No_BC_HH & 0.11 & 0.08 & 0.08 & 0.95 & 0.03 & 0.10 & 0.05 & 0.04 & -0.04 & -0.09 & 0.05 & 0.07 & 0.00 & 0.07 & 0.02 & 0.02 & 0.02 & -0.03 & -0.04 & -0.02 & 0.03 & -0.05 \\
\hline & No_BC_boys & 0.15 & 0.02 & 0.08 & 0.79 & 0.04 & 0.01 & -0.04 & -0.01 & 0.03 & -0.08 & 0.00 & 0.07 & 0.05 & 0.11 & -0.05 & -0.07 & -0.02 & -0.01 & 0.02 & 0.02 & 0.00 & -0.03 \\
\hline & Tot_HH_size & 0.15 & 0.10 & 0.13 & 0.78 & 0.06 & 0.13 & 0.08 & 0.05 & 0.02 & 0.43 & 0.07 & 0.13 & 0.05 & 0.10 & 0.04 & 0.02 & 0.06 & -0.02 & -0.02 & -0.01 & 0.04 & -0.03 \\
\hline & Mean_age_BC & 0.07 & -0.07 & 0.04 & 0.76 & 0.05 & 0.09 & -0.01 & -0.01 & 0.02 & 0.07 & -0.29 & 0.05 & 0.1 & -0.03 & 0.01 & -0.05 & 0.02 & 0.07 & 0.08 & 0.10 & -0.12 & 0.13 \\
\hline & No_BC_girls & 0.02 & 0.10 & 0.03 & 0.70 & 0.02 & 0.18 & 0.12 & 0.08 & -0.06 & -0.07 & 0.08 & 0.04 & -0.03 & 0.03 & 0.09 & 0.12 & 0.05 & -0.06 & -0.09 & -0.04 & 0.06 & -0.05 \\
\hline & Mean_Educ_BC & 0.09 & -0.09 & 0.05 & 0.67 & 0.06 & 0.06 & 0.04 & -0.03 & 0.04 & 0.08 & -0.20 & 0.05 & 0.21 & -0.02 & -0.02 & 0.02 & -0.02 & 0.11 & 0.12 & 0.13 & -0.13 & 0.26 \\
\hline \multirow{4}{*}{$\begin{array}{l}\text { Agricultural } \\
\text { Extension } \\
\text { activities }\end{array}$} & $\begin{array}{l}\text { Hrs_extension_meetings } \\
\text { dry season }\end{array}$ & 0.08 & 0.15 & 0.13 & 0.07 & 0.92 & 0.05 & 0.04 & 0.11 & 0.10 & 0.06 & 0.03 & 0.03 & 0.07 & 0.03 & -0.01 & 0.02 & 0.07 & 0.07 & -0.02 & -0.02 & 0.09 & 0.04 \\
\hline & $\begin{array}{l}\text { Hrs_extension_meetings } \\
\text { wet season }\end{array}$ & 0.08 & 0.15 & 0.13 & 0.07 & 0.92 & 0.04 & 0.04 & 0.12 & 0.10 & 0.06 & 0.04 & 0.04 & 0.09 & 0.04 & -0.01 & 0.01 & 0.07 & 0.06 & -0.04 & -0.02 & 0.08 & 0.04 \\
\hline & $\begin{array}{l}\text { HHL_extension_meetings } \\
\text { wet season }\end{array}$ & 0.07 & 0.15 & 0.12 & 0.05 & 0.91 & 0.10 & 0.09 & 0.11 & 0.10 & 0.09 & 0.02 & 0.11 & 0.07 & 0.02 & -0.02 & 0.03 & 0.05 & 0.09 & -0.03 & 0.04 & 0.05 & 0.03 \\
\hline & HHL_extension_meetings & 0.08 & 0.15 & 0.13 & 0.04 & 0.90 & 0.10 & 0.08 & 0.11 & 0.09 & 0.10 & 0.02 & 0.11 & 0.07 & 0.02 & -0.01 & 0.03 & 0.05 & 0.10 & -0.04 & 0.04 & 0.06 & 0.03 \\
\hline
\end{tabular}


dry season

\begin{tabular}{|c|c|c|c|c|c|c|c|c|c|c|c|c|c|c|c|c|c|c|c|c|c|c|c|}
\hline & dry season & & & & & & & & & & & & & & & & & & & & & & \\
\hline \multirow[t]{6}{*}{$\begin{array}{l}\text { Cultivation } \\
\text { labour input }\end{array}$} & $\begin{array}{l}\text { HHL_opening_agric.land } \\
\text { wet season }\end{array}$ & 0.42 & 0.12 & 0.09 & 0.14 & 0.08 & 0.75 & -0.01 & 0.09 & 0.05 & 0.09 & -0.03 & 0.14 & 0.09 & 0.11 & 0.02 & -0.01 & 0.03 & -0.03 & -0.03 & 0.01 & 0.08 & 0.08 \\
\hline & $\begin{array}{l}\text { HHL_opening_agric.land } \\
\text { dry season }\end{array}$ & 0.42 & 0.12 & 0.09 & 0.15 & 0.07 & 0.75 & -0.02 & 0.10 & 0.05 & 0.10 & -0.04 & 0.15 & 0.09 & 0.10 & 0.03 & 0.01 & 0.03 & 0.01 & -0.04 & -0.01 & 0.53 & 0.10 \\
\hline & HHL_weeding wet season & 0.44 & 0.11 & 0.09 & 0.15 & 0.08 & 0.73 & -0.04 & 0.10 & -0.01 & 0.15 & -0.02 & 0.19 & 0.02 & 0.10 & 0.03 & -0.01 & 0.03 & -0.03 & -0.05 & 0.02 & 0.03 & 0.02 \\
\hline & HHL_weeding dry season & 0.45 & 0.11 & 0.09 & 0.15 & 0.07 & 0.69 & 0.01 & 0.10 & 0.02 & 0.14 & -0.04 & 0.14 & -0.01 & 0.11 & 0.04 & -0.06 & 0.01 & -0.04 & -0.05 & 0.03 & -0.01 & 0.04 \\
\hline & $\begin{array}{l}\text { HHL_postharvest_handling } \\
\text { wet season }\end{array}$ & 0.47 & 0.03 & 0.03 & 0.08 & 0.08 & 0.66 & -0.03 & 0.04 & 0.09 & -0.10 & 0.02 & 0.13 & 0.14 & 0.08 & -0.04 & -0.04 & -0.09 & 0.09 & 0.02 & 0.02 & -0.03 & -0.12 \\
\hline & $\begin{array}{l}\text { HHL_postharvest_handling } \\
\text { dry season }\end{array}$ & 0.47 & 0.04 & 0.03 & 0.09 & 0.08 & 0.65 & -0.04 & 0.04 & 0.09 & -0.09 & 0.02 & 0.13 & 0.14 & 0.08 & -0.03 & $\begin{array}{l}-0.04 \\
\end{array}$ & -0.10 & 0.08 & 0.02 & 0.04 & -0.02 & 0.12 \\
\hline \multirow{4}{*}{$\begin{array}{l}\text { Household } \\
\text { groceries } \\
\text { shopping }\end{array}$} & $\begin{array}{l}\text { Hrs_grocery_shopping wet } \\
\text { season }\end{array}$ & 0.18 & -0.05 & 0.12 & 0.04 & 0.03 & -0.04 & 0.91 & 0.02 & 0.02 & -0.02 & 0.02 & -0.08 & 0.03 & 0.03 & 0.02 & -0.13 & 0.04 & 0.07 & 0.02 & 0.01 & 0.04 & -0.03 \\
\hline & $\begin{array}{l}\text { Hrs_grocery_shopping dry } \\
\text { season }\end{array}$ & 0.19 & -0.04 & 0.01 & 0.04 & 0.03 & -0.04 & 0.91 & 0.02 & 0.02 & -0.01 & 0.02 & -0.09 & 0.03 & 0.03 & 0.02 & -0.13 & 0.04 & 0.06 & 0.02 & 0.01 & 0.04 & -0.03 \\
\hline & $\begin{array}{l}\text { HHL_grocery_shopping } \\
\text { dry season }\end{array}$ & 0.16 & 0.01 & 0.01 & 0.05 & 0.09 & 0.02 & 0.90 & 0.00 & 0.01 & 0.12 & 0.01 & 0.16 & -0.01 & -0.04 & -0.01 & -0.08 & 0.05 & 0.01 & 0.01 & -0.02 & -0.05 & 0.03 \\
\hline & $\begin{array}{l}\text { HHL_grocery_shopping } \\
\text { wet season }\end{array}$ & 0.16 & 0.02 & 0.01 & 0.05 & 0.09 & 0.02 & 0.90 & 0.02 & 0.00 & 0.12 & 0.01 & 0.16 & -0.01 & 0.00 & $\begin{array}{c}-0.01 \\
\end{array}$ & $\begin{array}{l}-0.07 \\
\end{array}$ & 0.05 & 0.01 & 0.00 & -0.01 & -0.05 & 0.03 \\
\hline \multirow[t]{4}{*}{$\begin{array}{l}\text { On-farm } \\
\text { expenditure }\end{array}$} & $\begin{array}{l}\text { Tot_expenditure_crop } \\
\text { previous season }\end{array}$ & 0.18 & 0.17 & 0.11 & 0.03 & 0.11 & 0.08 & 0.03 & 0.87 & 0.10 & 0.01 & 0.07 & 0.03 & 0.12 & 0.01 & -0.01 & 0.03 & -0.03 & 0.05 & -0.02 & 0.04 & 0.03 & 0.03 \\
\hline & $\begin{array}{l}\text { Tot_on-farm_expenditure } \\
2012\end{array}$ & 0.18 & 0.16 & 0.18 & 0.03 & 0.13 & 0.07 & 0.03 & 0.87 & 0.12 & 0.04 & 0.08 & 0.02 & 0.09 & 0.02 & -0.01 & 0.02 & -0.01 & 0.06 & $\begin{array}{c}-0.02 \\
\end{array}$ & 0.09 & 0.00 & 0.02 \\
\hline & $\begin{array}{l}\text { Tot_expenditure_crop } \\
\text { current season }\end{array}$ & 0.14 & 0.24 & 0.10 & 0.03 & 0.11 & 0.10 & -0.02 & 0.86 & 0.10 & 0.01 & 0.09 & 0.03 & 0.11 & -0.03 & -0.03 & 0.03 & 0.02 & 0.03 & -0.01 & -0.02 & 0.02 & 0.01 \\
\hline & $\begin{array}{l}\text { Tot_on-farm_expenditure } \\
2013\end{array}$ & 0.14 & 0.23 & 0.18 & 0.02 & 0.11 & 0.08 & 0.02 & 0.85 & 0.11 & 0.04 & 0.09 & 0.02 & 0.08 & 0.00 & -0.03 & 0.02 & 0.02 & 0.04 & 0.01 & 0.04 & 0.02 & -0.01 \\
\hline \multirow[t]{4}{*}{$\begin{array}{l}\text { Pest-control } \\
\text { activities }\end{array}$} & $\begin{array}{l}\text { HHL_pest_control dry } \\
\text { season }\end{array}$ & 0.02 & 0.10 & -0.02 & 0.01 & 0.10 & 0.11 & 0.01 & 0.09 & 0.90 & 0.02 & 0.04 & -0.04 & 0.06 & -0.04 & 0.04 & 0.04 & -0.04 & 0.01 & 0.02 & 0.03 & 0.06 & 0.02 \\
\hline & $\begin{array}{l}\text { Hrs_pest_control dry } \\
\text { season }\end{array}$ & 0.07 & 0.11 & 0.07 & 0.02 & 0.06 & -0.03 & 0.00 & 0.07 & 0.89 & 0.06 & 0.04 & 0.00 & 0.10 & 0.12 & -0.07 & -0.01 & 0.03 & 0.06 & -0.01 & -0.01 & 0.08 & -0.03 \\
\hline & $\begin{array}{l}\text { Hrs_pest_control wet } \\
\text { season }\end{array}$ & 0.06 & 0.12 & 0.05 & -0.01 & 0.06 & -0.05 & 0.02 & 0.10 & 0.88 & 0.06 & 0.04 & -0.01 & 0.12 & 0.02 & -0.07 & -0.01 & 0.02 & 0.07 & -0.02 & -0.01 & 0.07 & -0.02 \\
\hline & $\begin{array}{l}\text { HHL_pest_control wet } \\
\text { season }\end{array}$ & 0.01 & 0.06 & 0.03 & 0.00 & 0.11 & 0.13 & 0.01 & 0.09 & 0.88 & -0.02 & 0.03 & -0.04 & 0.04 & -0.04 & 0.04 & 0.12 & -0.01 & -0.02 & 0.00 & 0.02 & 0.02 & 0.01 \\
\hline \multirow{3}{*}{$\begin{array}{l}\text { Extended } \\
\text { family } \\
\text { characteristics }\end{array}$} & No_other_relatives_HH & 0.08 & 0.06 & 0.10 & 0.01 & 0.09 & 0.05 & 0.07 & 0.03 & 0.06 & 0.95 & 0.14 & -0.04 & 0.06 & -0.01 & -0.02 & 0.02 & 0.06 & 0.04 & 0.02 & -0.03 & 0.03 & 0.03 \\
\hline & No_other_relatives_male & 0.10 & 0.04 & 0.10 & 0.02 & 0.09 & 0.04 & 0.02 & 0.00 & 0.03 & 0.86 & -0.04 & 0.11 & 0.06 & 0.00 & 0.02 & 0.01 & 0.07 & 0.06 & $\begin{array}{c}-0.01 \\
\end{array}$ & 0.04 & 0.09 & 0.06 \\
\hline & No_other_relatives_female & 0.06 & 0.05 & 0.08 & -0.01 & 0.07 & 0.07 & 0.08 & 0.04 & 0.07 & 0.83 & -0.03 & 0.14 & 0.04 & -0.03 & -0.05 & 0.02 & 0.03 & -0.01 & 0.03 & -0.04 & -0.09 & -0.02 \\
\hline \multirow{4}{*}{$\begin{array}{l}\text { Education } \\
\text { level }\end{array}$} & Educ_respondent & -0.01 & 0.05 & 0.01 & -0.01 & 0.04 & 0.03 & -0.02 & 0.04 & 0.06 & 0.07 & 0.82 & -0.01 & 0.09 & -0.10 & -0.05 & 0.03 & 0.01 & 0.04 & 0.02 & 0.02 & -0.12 & 0.05 \\
\hline & Educ_father & 0.01 & 0.04 & -0.03 & 0.02 & 0.03 & -0.03 & 0.04 & 0.11 & 0.02 & -0.07 & 0.77 & -0.02 & 0.06 & 0.01 & -0.05 & -0.05 & -0.01 & 0.05 & -0.01 & -0.02 & 0.05 & 0.01 \\
\hline & Educ_mother & -0.06 & 0.07 & -0.02 & -0.02 & 0.04 & -0.04 & 0.01 & 0.08 & 0.05 & 0.02 & 0.76 & -0.05 & 0.03 & -0.18 & 0.01 & 0.06 & 0.07 & 0.02 & 0.04 & 0.00 & -0.08 & -0.02 \\
\hline & Respondent's age & -0.01 & -0.06 & -0.01 & 0.21 & 0.07 & -0.03 & -0.03 & 0.01 & -0.02 & 0.13 & -0.62 & -0.04 & 0.08 & 0.02 & 0.08 & 0.09 & 0.05 & 0.06 & 0.03 & 0.05 & -0.29 & -0.03 \\
\hline \multirow{2}{*}{$\begin{array}{l}\text { Labour input } \\
\text { for food } \\
\text { preparation } \\
\text { and fetching }\end{array}$} & $\begin{array}{l}\text { HHL_food_preparation dry } \\
\text { season }\end{array}$ & 0.06 & -0.03 & 0.01 & 0.10 & 0.07 & 0.17 & 0.02 & 0.04 & -0.01 & 0.15 & -0.01 & 0.90 & 0.02 & 0.01 & -0.01 & -0.06 & 0.10 & 0.05 & 0.05 & 0.02 & -0.04 & 0.02 \\
\hline & $\begin{array}{l}\text { HHL_food_preparation } \\
\text { wet season }\end{array}$ & 0.05 & -0.04 & 0.01 & 0.11 & 0.07 & 0.18 & 0.01 & 0.03 & -0.02 & 0.15 & -0.02 & 0.90 & 0.02 & 0.01 & -0.01 & -0.06 & 0.10 & 0.06 & 0.05 & 0.03 & -0.04 & 0.02 \\
\hline
\end{tabular}




\begin{tabular}{|c|c|c|c|c|c|c|c|c|c|c|c|c|c|c|c|c|c|c|c|c|c|c|c|}
\hline \multirow[t]{2}{*}{ water } & $\begin{array}{l}\text { HHL_fetching_water dry } \\
\text { season }\end{array}$ & 0.11 & 0.20 & 0.02 & 0.22 & 0.20 & 0.21 & 0.18 & 0.04 & -0.06 & 0.27 & -0.02 & 0.54 & 0.02 & 0.13 & 0.33 & 0.12 & 0.10 & -0.10 & 0.07 & -0.02 & 0.05 & 0.09 \\
\hline & $\begin{array}{l}\text { HHL_fetching_water wet } \\
\text { season }\end{array}$ & 0.11 & 0.20 & 0.02 & 0.21 & 0.20 & 0.21 & 0.18 & 0.03 & -0.03 & 0.27 & -0.02 & 0.54 & 0.03 & 0.15 & 0.31 & 0.14 & 0.11 & -0.08 & 0.08 & -0.02 & 0.04 & 0.10 \\
\hline \multirow{5}{*}{$\begin{array}{l}\text { Agricultural } \\
\text { implements } \\
\text { and farm size }\end{array}$} & Tot_No_farm_implements & 0.15 & 0.22 & 0.13 & 0.16 & 0.13 & 0.34 & 0.06 & 0.19 & 0.12 & 0.11 & 0.07 & -0.03 & 0.73 & 0.10 & 0.06 & -1.00 & 0.03 & 0.05 & 0.05 & 0.07 & -0.03 & 0.03 \\
\hline & Tot_No_low_input tools & 0.16 & 0.21 & 0.12 & 0.16 & 0.12 & 0.36 & 0.07 & 0.20 & 0.10 & 0.10 & 0.06 & -0.03 & 0.69 & 0.11 & 0.08 & -0.11 & 0.05 & 0.04 & 0.05 & 0.08 & -0.03 & 0.01 \\
\hline & Tot_No_high_input tools & 0.01 & 0.19 & 0.11 & 0.02 & 0.16 & -0.02 & -0.02 & 0.15 & 0.26 & 0.15 & 0.07 & 0.04 & 0.55 & -0.10 & -0.08 & 0.08 & -0.08 & 0.10 & 0.03 & 0.05 & 0.02 & 0.20 \\
\hline & $\begin{array}{l}\text { Tot_farmland_size } \\
\text { previous season }\end{array}$ & 0.46 & 0.32 & 0.22 & 0.12 & 0.07 & -0.08 & -0.03 & 0.15 & 0.18 & -0.04 & 0.06 & 0.14 & 0.54 & -0.07 & -0.02 & 0.13 & -0.04 & 0.06 & -0.04 & -0.08 & 0.17 & 0.04 \\
\hline & $\begin{array}{l}\text { Tot_farmland_size current } \\
\text { season }\end{array}$ & 0.44 & 0.35 & 0.23 & 0.15 & 0.07 & -0.08 & -0.03 & 0.16 & 0.16 & -0.04 & -0.06 & 0.14 & 0.53 & -0.06 & -0.06 & 0.11 & -0.03 & 0.05 & -0.05 & -0.08 & 0.15 & 0.04 \\
\hline \multirow[t]{3}{*}{$\begin{array}{l}\text { Firewood } \\
\text { gathering }\end{array}$} & $\begin{array}{l}\text { Hrs_gathering_firewood } \\
\text { wet season }\end{array}$ & 0.34 & 0.03 & 0.05 & 0.07 & 0.00 & 0.10 & 0.03 & -0.03 & -0.04 & -0.03 & -0.18 & 0.05 & -0.05 & 0.83 & 0.19 & -0.08 & -0.02 & -0.02 & -0.03 & 0.00 & -0.01 & -0.03 \\
\hline & $\begin{array}{l}\text { Hrs_gathering_firewood } \\
\text { dry season }\end{array}$ & 0.34 & 0.02 & 0.04 & 0.07 & 0.00 & 0.10 & 0.03 & -0.03 & -0.04 & -0.03 & -0.18 & 0.06 & -0.05 & 0.83 & 0.20 & -0.07 & -0.02 & -0.04 & -0.03 & -0.01 & -0.02 & -0.02 \\
\hline & $\begin{array}{l}\text { Annual volume firewood } \\
\text { gathered }\end{array}$ & 0.17 & 0.10 & 0.11 & 0.15 & 0.12 & 0.29 & 0.00 & 0.07 & 0.01 & 0.06 & -0.08 & 0.14 & 0.14 & 0.68 & 0.02 & -0.03 & 0.12 & 0.04 & -0.01 & -0.08 & 0.11 & 0.01 \\
\hline \multirow[t]{2}{*}{$\begin{array}{l}\text { Fetching water } \\
\text { time budget }\end{array}$} & $\begin{array}{l}\text { Hrs_fetching_water wet } \\
\text { season }\end{array}$ & 0.20 & -0.07 & -0.01 & 0.02 & -0.03 & 0.01 & 0.00 & -0.04 & -0.03 & -0.03 & -0.07 & 0.04 & 0.01 & 0.14 & 0.93 & -0.07 & 0.12 & 0.01 & -0.01 & 0.01 & 0.02 & -0.03 \\
\hline & $\begin{array}{l}\text { Hrs_fetching_water dry } \\
\text { season }\end{array}$ & 0.18 & -0.06 & -0.02 & 0.02 & -0.03 & 0.01 & -0.03 & -0.03 & -0.02 & -0.04 & -0.08 & 0.06 & 0.00 & 0.14 & 0.93 & -0.02 & 0.02 & 0.02 & -0.03 & 0.01 & 0.01 & -0.01 \\
\hline \multirow{2}{*}{$\begin{array}{l}\text { Trading own- } \\
\text { shop time } \\
\text { budget }\end{array}$} & $\begin{array}{l}\text { Hrs_trading_own_shop } \\
\text { dry season }\end{array}$ & -0.06 & -0.02 & -0.04 & 0.02 & 0.04 & -0.04 & -0.20 & 0.04 & 0.02 & 0.03 & 0.05 & -0.02 & -0.04 & -0.07 & -0.01 & 0.95 & 0.11 & 0.05 & 0.02 & 0.01 & -0.03 & -0.01 \\
\hline & $\begin{array}{l}\text { Hrs_trading_own_shop } \\
\text { wet season }\end{array}$ & -0.06 & -0.02 & -0.04 & 0.02 & 0.04 & -0.04 & -0.20 & 0.04 & 0.02 & 0.03 & 0.05 & -0.02 & -0.04 & -0.07 & -0.01 & 0.95 & 0.11 & 0.05 & 0.02 & 0.01 & -0.03 & -0.01 \\
\hline \multirow{2}{*}{$\begin{array}{l}\text { Food } \\
\text { preparation } \\
\text { time budget }\end{array}$} & $\begin{array}{l}\text { Hrs_food_preparation dry } \\
\text { season }\end{array}$ & 0.15 & 0.03 & 0.03 & 0.04 & 0.10 & -0.02 & 0.02 & -0.01 & 0.01 & 0.01 & 0.01 & 0.01 & -0.01 & 0.03 & 0.02 & 0.01 & 0.95 & 0.04 & 0.02 & 0.01 & -0.01 & 0.01 \\
\hline & $\begin{array}{l}\text { Hrs_food_preparation wet } \\
\text { season }\end{array}$ & 0.15 & 0.04 & 0.02 & 0.04 & 0.10 & -0.02 & 0.02 & -0.01 & 0.01 & 0.01 & 0.01 & 0.01 & -0.01 & 0.03 & 0.02 & 0.01 & 0.95 & 0.05 & 0.02 & 0.01 & -0.01 & 0.01 \\
\hline \multirow{2}{*}{$\begin{array}{l}\text { Selling } \\
\text { agricultural } \\
\text { produce time } \\
\text { budget }\end{array}$} & $\begin{array}{l}\text { Hrs_selling_agric.produce } \\
\text { dry season }\end{array}$ & 0.19 & 0.37 & 0.13 & 0.01 & 0.22 & 0.04 & 0.20 & 0.11 & 0.09 & 0.06 & 0.06 & 0.04 & 0.10 & 0.02 & 0.02 & 0.07 & 0.07 & 0.80 & 0.00 & 0.01 & 0.11 & 0.04 \\
\hline & $\begin{array}{l}\text { Hrs_selling_agric.produce } \\
\text { wet season }\end{array}$ & 0.19 & 0.37 & 0.12 & 0.01 & 0.22 & 0.03 & 0.11 & 0.11 & 0.09 & 0.06 & 0.07 & 0.05 & 0.10 & 0.02 & 0.02 & 0.08 & 0.08 & 0.80 & -0.02 & 0.02 & 0.11 & 0.04 \\
\hline \multirow[t]{2}{*}{ Marriage age } & Clan_marriage_age_girls & 0.03 & 0.01 & 0.04 & -0.02 & -0.08 & 0.02 & -0.04 & -0.01 & 0.01 & -0.04 & 0.05 & 0.04 & 0.02 & -0.03 & 0.06 & -0.04 & 0.02 & 0.01 & 0.86 & -0.06 & 0.05 & -0.04 \\
\hline & Clan_marriage_age_boys & 0.04 & 0.04 & -0.01 & 0.05 & -0.01 & -0.09 & 0.08 & -0.01 & -0.02 & 0.08 & -0.03 & 0.08 & 0.02 & -0.02 & -0.06 & 0.09 & 0.01 & -0.01 & 0.84 & 0.01 & -0.02 & 0.09 \\
\hline \multirow[t]{2}{*}{$\begin{array}{l}\text { Livestock } \\
\text { income }\end{array}$} & $\begin{array}{l}\text { Tot_income_livestock } \\
2013\end{array}$ & 0.02 & 0.11 & 0.14 & 0.06 & -0.03 & 0.03 & -0.01 & 0.06 & 0.03 & -0.04 & -0.02 & 0.04 & -0.02 & -1.00 & 0.02 & 0.04 & 0.01 & 0.04 & -0.06 & 0.72 & 0.16 & -0.07 \\
\hline & $\begin{array}{l}\text { Tot_income_livestock } \\
2012\end{array}$ & 0.02 & 0.23 & 0.43 & 0.05 & 0.11 & 0.12 & 0.01 & 0.07 & -0.03 & 0.10 & -0.01 & -0.08 & 0.15 & -0.01 & $\begin{array}{l}-0.02 \\
\end{array}$ & 0.06 & 0.02 & -0.09 & -0.01 & 0.47 & 0.13 & 0.5 \\
\hline \multirow{2}{*}{$\begin{array}{l}\text { Forest } \\
\text { products used }\end{array}$} & Quantity of poles & -0.07 & 0.09 & -0.05 & -0.06 & 0.12 & 0.06 & 0.07 & 0.01 & 0.05 & 0.00 & -0.01 & -0.06 & 0.09 & 0.05 & -0.02 & -0.02 & 0.06 & 0.11 & 0.04 & 0.09 & 0.75 & -0.62 \\
\hline & Quantity of timber & 0.01 & 0.07 & 0.12 & 0.03 & 0.17 & -0.03 & -0.12 & 0.06 & 0.29 & 0.06 & 0.03 & 0.01 & -0.06 & -0.01 & 0.09 & -0.07 & -0.09 & 0.02 & -0.01 & 0.13 & 0.61 & 0.03 \\
\hline \multirow{2}{*}{$\begin{array}{l}\text { HH off-farm } \\
\text { income }\end{array}$} & HH_off-farm_income_BC & -0.01 & 0.07 & 0.17 & 0.06 & 0.04 & 0.06 & 0.02 & -0.04 & -0.03 & 0.06 & -0.01 & 0.07 & 0.10 & 0.03 & 0.02 & -0.04 & -0.02 & 0.02 & 0.04 & -0.06 & -0.03 & 0.80 \\
\hline & HH_tot_off-farm_income & -0.14 & -0.02 & -0.02 & 0.02 & 0.15 & -0.13 & -0.05 & 0.24 & 0.04 & -0.03 & 0.38 & 0.05 & 0.03 & -0.16 & 0.04 & -0.03 & -0.05 & 0.08 & 0.03 & 0.10 & -0.03 & 0.49 \\
\hline
\end{tabular}

